\title{
Benefits of VCE-003.2, a cannabigerol quinone derivative, against inflammation- driven neuronal deterioration in experimental Parkinson's disease: possible involvement of different binding sites at the PPARY receptor
}

Concepción García ${ }^{1,2,3}$, María Gómez-Cañas ${ }^{1,2,3}$, Sonia Burgaz,2,3, Belén Palomares ${ }^{4,5,6}$, Yolanda Gómez-Gálvez ${ }^{1,9}$, Cristina Palomo-Garo ${ }^{1,2,3}$, Sara Campo ${ }^{1}$, Joel Ferrer-Hernández ${ }^{1}$, Carolina Pavicic ${ }^{7}$, Carmen Navarrete ${ }^{8}$, M. Luz Bellido ${ }^{8}$, Moisés García-Arencibia ${ }^{1,2,3,10}$, M. Ruth Pazos ${ }^{1,2,3,11}$, Eduardo Muñoz ${ }^{4,5,6}$ and Javier Fernández-Ruiz ${ }^{1,2,3^{*}}$

\begin{abstract}
Background: Neuroprotection with cannabinoids in Parkinson's disease (PD) has been afforded predominantly with antioxidant or anti-inflammatory cannabinoids. In the present study, we investigated the anti-inflammatory and neuroprotective properties of VCE-003.2, a quinone derivative of the non-psychotrophic phytocannabinoid cannabigerol (CBG), which may derive its activity at the peroxisome proliferator-activated receptor- $\gamma$ (PPAR $)$. The compound is also an antioxidant.
\end{abstract}

Methods: We evaluated VCE-003.2 in an in vivo [mice subjected to unilateral intrastriatal injections of lipopolysaccharide (LPS)] model of PD, as well as in in vitro (LPS-exposed BV2 cells and M-213 cells treated with conditioned media generated from LPS-exposed BV2 cells) cellular models. The type of interaction of VCE-003.2 at the PPARY receptor was furtherly investigated in bone marrow-derived human mesenchymal stem cells (MSCs) and sustained with transcriptional assays and in silico docking studies.

(Continued on next page)

\footnotetext{
* Correspondence: jjif@med.ucm.es

${ }^{1}$ Instituto Universitario de Investigación en Neuroquímica, Departamento de

Bioquímica y Biología Molecular, Facultad de Medicina, Universidad

Complutense, 28040 Madrid, Spain

${ }^{2}$ Centro de Investigación Biomédica en Red de Enfermedades

Neurodegenerativas (CIBERNED), Madrid, Spain

Full list of author information is available at the end of the article
} 
(Continued from previous page)

Results: VCE-003.2 has no activity at the cannabinoid receptors, a fact that we confirmed in this study using competition studies. The administration of VCE-003.2 to LPS-lesioned mice attenuated the loss of tyrosine hydroxylase (TH)-containing nigrostriatal neurons and, in particular, the intense microgliosis provoked by LPS in the substantia nigra, measured by 1 ba- $1 / C d 68$ immunostaining. The analysis by $\mathrm{qPCR}$ of proinflammatory mediators such as tumor necrosis factor- $\alpha$ (TNF- $a$ ), interleukin-1 $\beta$ (IL-1 $\beta$ ), and inducible nitric oxide synthase (iNOS) in the striatum showed they were markedly elevated by the LPS lesion and strongly reduced by the treatment with VCE-003.2. The effects of VCE-003.2 in LPS-lesioned mice implied the activation of PPARY receptors, as they were attenuated when VCE-003.2 was co-administered with the PPARY inhibitor T0070907. We then moved to some in vitro approaches, first to confirm the anti-inflammatory profile of VCE-003.2 in cultured BV2 cells exposed to LPS. VCE-003.2 was able to attenuate the synthesis and release of TNF-a and IL$1 \beta$, as well as the induction of iNOS and cyclooxygenase-2 (COX-2) elicited by LPS in these cells. However, we found such effects were not reversed by GW9662, another classic PPARY antagonist. Next, we investigated the neuroprotective effects of VCE-003.2 in cultured M-213 neuronal cells exposed to conditioned media generated from LPS-exposed cultured BV2 cells. VCE-003.2 reduced M-213 cell death, but again, such effects were not reversed by T0070907. Using docking analysis, we detected that VCE-003.2 binds both the canonical and the alternative binding sites in the PPARY ligand-binding pocket (LBP). Functional assays further showed that T0070907 almost abolished PPARY transcriptional activity induced by rosiglitazone (RGZ), but it did not affect the activity of VCE-003.2 in a Gal4-Luc system. However, T0070907 inhibited the effects of RGZ and VCE-003.2 on the expression of PPARY-dependent genes upregulated in MSCS.

Conclusions: We have demonstrated that VCE-003.2 is neuroprotective against inflammation-driven neuronal damage in an in vivo model of PD and in in vitro cellular models of neuroinflammation. Such effects might involve PPARY receptors, although in silico and in vitro experiments strongly suggest that VCE-003.2 targets PPARY by acting through two binding sites at the LBP, one that is sensitive to T0070907 (canonical binding site) and other that is not affected by this PPARY antagonist (alternative binding site).

Keywords: Cannabinoids, VCE-003.2, PPARy receptors, Inflammation, Microglial activation, LPS, Parkinson's disease

\section{Background}

Inflammation is a key pathogenic event in Parkinson's disease (PD), so that anti-inflammatory strategies are being investigated to limit neuronal deterioration in this disease [1]. Certain cannabinoids have proved important anti-inflammatory/neuroprotective properties, which have been primarily assigned to the role exerted by the cannabinoid receptor type- $2\left(\mathrm{CB}_{2}\right)$ in the control of glia-dependent inflammatory events typical of neurodegenerative/neuroinflammatory disorders [2, 3]. However, its relevance in PD has remained elusive for years. A few years ago, Price and coworkers [4] described an elevation of $\mathrm{CB}_{2}$ receptors in microglial cells recruited at the lesion sites in mice intoxicated with MPTP, a model with a modest glial response. These authors found that targeting these receptors reduced the damage of nigrostriatal neurons [4], although a further study showed that the inhibition of microglial activation and the preservation of nigrostriatal dopaminergic neurons in MPTP-lesioned mice involved surprisingly the activation of the cannabinoid receptor type-1 $\left(\mathrm{CB}_{1}\right)$ too [5]. In our laboratory, we worked with postmortem basal ganglia collected from $\mathrm{PD}$ patients and confirmed such upregulatory response of $\mathrm{CB}_{2}$ receptors in glial elements [6]. We also investigated the issue in an inflammatory model of nigrostriatal damage consisting in intrastriatal injection of lipopolysaccharide (LPS), in which we found elevated levels of $\mathrm{CB}_{2}$ receptors in the basal ganglia $[6,7]$. Such receptors may be apparently located in activated glial elements, although we did not investigate the cell substrates in which this response takes place. In addition, we found that $\mathrm{CB}_{2}$ receptor-deficient mice were more vulnerable to LPS lesion than wild-type animals [6,7], a difference that was not found in a model with poor inflammatory responses, mice lesioned with 6-hydroxydopamine, in which the death of dopaminergic neurons is related to mitochondrial dysfunction and oxidative damage [7]. In agreement with this difference, LPS-lesioned mice responded to compounds targeting the $\mathrm{CB}_{2}$ receptor by preserving tyrosine hydroxylase $(\mathrm{TH})$-containing neurons and by reducing microglial reactivity and macrophage infiltration [6, 7]. In contrast, 6-hydroxydopamine-lesioned mice did not respond to $\mathrm{CB}_{2}$ receptor activation [8]. Such differences were recently confirmed by Concannon and coworkers [9] who compared the elevation of $\mathrm{CB}_{2}$ receptors in LPSlesioned rats, which was paralleled by increased microglial activation, with the poor response found in rodents lesioned with 6-hydroxydopamine. However, work conducted by Ternianov and coworkers [10] supported a role 
of $\mathrm{CB}_{2}$ receptors in 6-hydroxydopamine-lesioned mice too, as they found that mice overexpressing $\mathrm{CB}_{2}$ receptors were more protected against 6-hydroxydopamine-induced nigrostriatal damage.

The anti-inflammatory potential of cannabinoids in PD has been recently reinforced with the possibility that some of them can also bind and activate specific receptor types of the peroxisome proliferator-activated receptor (PPAR) family such as PPAR $[11,12]$. Such nuclear receptors have long been involved in the control of neuroinflammatory responses [13], whereas specific non-cannabinoid PPAR $\gamma$ activators (e.g., thiazolidinediones) have been found to be active in experimental models of PD and have entered recently in clinical investigation [14]. Some endocannabinoids (e.g., anandamide and 2-arachidonoylglycerol) and their related signaling lipids (e.g., palmitoylethanolamide, oleylethanolamide), as well as different phytocannabinoids and their derivatives, have been found to exert PPAR $\gamma$ mediated anti-inflammatory activity $[12,15,16]$. We have recently designed, synthesized, and characterized different phytocannabinoid derivatives, in particular a series of quinone derivatives of cannabigerol (CBG) that behave as PPAR $\gamma$ activators [17-19], while retaining the lack of $\mathrm{CB}_{1} / \mathrm{CB}_{2}$ activity of their phytocannabinoid template. For this study, we were particularly interested in one non-thiophilic CBG quinone derivative, so-called VCE-003.2, whose ability to activate PPAR $\gamma$ [19] enables this compound to serve as an anti-inflammatory and a neuroprotectant in LPS-lesioned mice, the experimental model of PD that better reproduces inflammation as a pathogenic event in this disease. We have investigated VCE-003.2 in this in vivo PD model following previous research conducted in murine models of Huntington's disease [19], which confirmed its activity at the PPARY and its capability to cross the blood-brain barrier after systemic administration. In addition, we have extended this research with some in vitro experiments useful to confirm the anti-inflammatory profile of VCE-003.2 (cultured BV2 cells stimulated with LPS) or its neuroprotective effects (cultured M-213 neuronal cells incubated with conditioned media generated from cultured BV2 cells stimulated with LPS). In all these experimental approaches, the possible contribution of PPAR $\gamma$ activation has been investigated using selective inhibitors of these nuclear receptors. However, the lack of activity of classic PPARy antagonists (e.g., T0070907, GW9662) against VCE-003.2 effects in the in vitro studies and the recent identification of a functional alternative binding site for PPARy ligands that does not overlap with the canonical binding site used by glitazones [20] prompted us to investigate whether VCE-003.2 binds to this receptor at this different site using docking and transcriptional analyses. In an additional experiment presented as supplementary data (see Additional file 3), we have also investigated whether the cannabinoid receptor-independent antioxidant profile of VCE-003.2 enables this compound to also serve as neuroprotectant in 6-hydroxydopamine-lesioned mice, which is characterized, as mentioned above, by mitochondrial dysfunction and oxidative stress but having a poor inflammatory response. In this model, other antioxidant phytocannabinoids ( $\Delta^{9}$-tetrahydrocannabinol, cannabidiol, $\Delta^{9}$-tetrahydrocannabivarin) have been shown to preserve nigrostriatal dopaminergic neurons by antioxidant mechanisms independent of cannabinoid receptors $[7,8,21]$. With this study in whole, we expect to add experimental support to the idea that a pharmaceutical formulation, using a pleiotropic cannabinoid derivative targeting PPARy receptors, and perhaps other relevant targets for PD, may be of great interest to reduce inflammation and oxidative stress, as well as to enhance neuronal integrity in PD.

\section{Methods}

\section{Synthesis and receptor characterization of VCE-003.2}

The quinone derivative of CBG (6-(3,7)-dimethyl-octa2,6-dienyl)-5-hydroxy-3-pentyl-2-ethylamino-[1,4]benzoquinone), so-called VCE-003.2, was synthesized as described previously [19]. Its activity as a PPAR $\gamma$ activator was also previously characterized [19]. To confirm that, as expected, VCE-003.2 has no affinity at the $\mathrm{CB}_{1}$ and the $\mathrm{CB}_{2}$ receptors, we conducted radioligand binding assays using membranes purified from cells transfected with human $\mathrm{CB}_{1}$ or $\mathrm{CB}_{2}$ receptors (RBHCB1M400UA and RBXCB2M400UA; Perkin-Elmer Life and Analytical Sciences, Boston, MA, USA). The protein concentration was $8 \mu \mathrm{g} /$ well for the $\mathrm{CB}_{1}$ receptor membranes and $4 \mu \mathrm{g} /$ well for those of the $\mathrm{CB}_{2}$ receptor. The binding buffer was $50 \mathrm{mM}$ Tris-Cl, $5 \mathrm{mM}$ $\mathrm{MgCl}_{2}, 2.5 \mathrm{mM}$ EDTA, and $0.5 \mathrm{mg} / \mathrm{mL}$ bovine serum albumin $(\mathrm{pH}=7.4)$ for $\mathrm{CB}_{1}$ and $50 \mathrm{mM}$ TrisCl, $5 \mathrm{mM}$ $\mathrm{MgCl}_{2}, 2.5 \mathrm{mM}$ EGTA, and $1 \mathrm{mg} / \mathrm{mL}$ bovine serum albumin $(\mathrm{pH}=7.5)$ for $\mathrm{CB}_{2}$. The radioligand was $\left[{ }^{3} \mathrm{H}\right]$ CP55940 (Perkin-Elmer) used at a concentration of membrane $\mathrm{K}_{\mathrm{D}} \times 0.8 \mathrm{nM}$, and the final incubation volume was $200 \mu \mathrm{l}$ for $\mathrm{CB}_{1}$ and $600 \mu \mathrm{l}$ for $\mathrm{CB}_{2}$. Ninetysix-well plates and the tubes necessary for the experiment were previously siliconized with Sigmacote (Sigma-Aldrich, Madrid, Spain). Membranes were resuspended in the corresponding buffer and were incubated $\left(90 \mathrm{~min}\right.$ at $\left.30{ }^{\circ} \mathrm{C}\right)$ with the radioligand and VCE-003.2 at a high concentration $(40 \mu \mathrm{M})$ with the purpose to determine the percentage of radioligand displacement. Non-specific binding was determined with $10 \mu \mathrm{M}$ WIN55212-2 and total radioligand binding by incubation with the membranes in absence of VCE003.2. Filtration was performed by a Harvester ${ }^{\circ}$ 
filtermate (Perkin-Elmer) with Filtermat A GF/C filters pretreated with polyethylenimine $0.05 \%$. After filtering, the filter was washed nine times with a binding buffer and dried and a melt-on scintillation sheet $\left(\right.$ Meltilex $^{\mathrm{Tm}} \mathrm{A}$, Perkin-Elmer) was melted onto it. Then, radioactivity was quantified by a liquid scintillation spectrophotometer (Wallac MicroBeta Trilux, Perkin-Elmer). In the case of both $\mathrm{CB}_{1}$ - and $\mathrm{CB}_{2}$-transfected membranes, radioligand displacement at these conditions was always lower than $50 \%$, then indicating negligible activity at both cannabinoid receptor types with $\mathrm{Ki}$ values in the micromolar range ( $>40 \mu \mathrm{M}$; data from at least 3 experiments performed in triplicate for each point).

\section{Cultures of BV2 cells and M-213 neuronal cells}

In a first experiment, mouse BV2 microglial cells (kindly provided by Dr. Carmen Guaza, Instituto Cajal, CSIC) were cultured in Dulbecco's modified Eagle's medium (DMEM, Lonza, Verviers, Belgium) supplemented with $10 \%$ fetal bovine serum (FBS, Sigma-Aldrich, Madrid, Spain), $2 \mathrm{mM}$ UltraGlutamine, and antibiotics (Lonza, Verviers, Belgium) in a humidified atmosphere of $5 \%$ $\mathrm{CO}_{2}$ at $37^{\circ} \mathrm{C}$. Cells were plated at a density of $45 \times 10^{4}$ cells per well in 12-well culture plates and incubated in DMEM with a reduction of FBS to $1 \%$. Three hours later, cells were treated with $0.5 \mu \mathrm{g} / \mathrm{ml}$ LPS (from Escherichia coli 055:B5, Sigma-Aldrich, Madrid, Spain), alone or in combination with VCE-003.2, used at a concentration of $5 \mu \mathrm{M}$ (selected from previous concentration-response studies), and added $1 \mathrm{~h}$ before LPS. Twenty hours after the addition of LPS, media were removed and used for the analysis of tumor necrosis factor- $\alpha$ $(\mathrm{TNF}-\alpha)$ and interleukin-1 $\beta$ (IL-1 $\beta$ ) levels using commercial ELISA kits (ref. MTA00B, R\&D Systems, Minneapolis, MN, USA for TNF- $\alpha$, and ref. MLB00C, R\&D Systems, Minneapolis, MN, USA for IL-1 $\beta$ ), whereas cell pellets were collected for analyzing protein levels by the Lowry method, which were used to normalize the cytokine data. In a follow-up experiment, the procedure for cell plating, incubation, and treatment with LPS and VCE-003.2 described above was repeated again, but an additional experimental group consisting of cells treated with LPS $(0.5 \mu \mathrm{g} / \mathrm{ml})$, VCE-003.2 $(5 \mu \mathrm{M})$, and GW9662 (10 $\mu \mathrm{M}$; Abcam, Cambridge, UK) was added. Twenty hours after the addition of LPS, cell pellets were collected for the GPCR analysis of TNF- $\alpha$, IL-1 $\beta$, inducible nitric oxide synthase (iNOS), and cyclooxygenase-2 (COX-2).

In a second experiment, cultured BV2 cells were maintained in DMEM (Lonza, Verviers, Belgium) supplemented with $10 \%$ fetal bovine serum (FBS, SigmaAldrich, Madrid, Spain), $2 \mathrm{mM}$ UltraGlutamine, and antibiotics (Lonza, Verviers, Belgium) in a humidified atmosphere of $5 \% \mathrm{CO}_{2}$ at $37{ }^{\circ} \mathrm{C}$. For experiments, cells were plated at a density of $2 \times 10^{5}$ cells per well in 6-well culture plates and incubated in DMEM with a reduction of FBS to $1 \%$. Three hours later, cells were treated with $0.5 \mu \mathrm{g} / \mathrm{ml}$ LPS (from Escherichia coli 055:B5, SigmaAldrich, Madrid, Spain). Twenty-four hours after the addition of LPS, media were removed to be added to cultures of the rat M-213 striatal cell line (kindly provided by Dr. WJ Freed, National Institute on Drug Abuse, Bethesda, MD, USA) to induce cell death following a procedure described previously [22]. To this end, M-213 cells were maintained in DMEM supplemented with 10\% FBS, $2 \mathrm{mM}$ UltraGlutamine, and $1 \%$ antibiotics (Lonza, Verviers, Belgium) under a humidified 5\% $\mathrm{CO}_{2}$ atmosphere at $37{ }^{\circ} \mathrm{C}$. For cytotoxicity experiments, cells were seeded at 50,000 cells/well in 24-well plates and maintained under a humidified atmosphere $\left(5 \% \mathrm{CO}_{2}\right)$ at $37{ }^{\circ} \mathrm{C}$ overnight. Afterwards, normal medium was completely replaced by the conditioned media generated in BV2 cell experiments, and then, M-213 cells were treated with the vehicle $(0.1 \% \mathrm{DMSO})$ or with three different concentrations of VCE-003.2 (0.1, 0.5, and $1 \mu \mathrm{M}$; selected according to our previously published study [19], which described an IC50 $=1.2 \mu \mathrm{M}$ for the binding of VCE003.2 to PPAR $\gamma$ receptors), added alone or combined with the selective PPAR $\gamma$ inhibitor T0070907 (10 $\mu \mathrm{M}$; Cayman Chemical, Ann Arbor, Michigan, USA). Rosiglitazone (RGZ) $(20 \mu \mathrm{M}$, according to [23] and laboratory experience; Sigma-Aldrich, Madrid, Spain) was also added, alone or combined with T0070907 $(10 \mu \mathrm{M})$, as a positive control for PPAR $\gamma$ activation. Cells were incubated for $40 \mathrm{~h}$ before the neuronal death was analyzed with the MTT assay (Panreac AppliChem., Barcelona, Spain). The data were normalized in relation with a control group consisting in M-213 cells exposed to conditioned media generated by BV2 cells in absence of LPS.

\section{Mesenchymal stem cell differentiation}

Human mesenchymal stem cells (MSCs) derived from bone marrow were obtained as previously described [19]. Cells were seeded in $\alpha$-MEM containing 15\% FCS, 2 mM UltraGlutamine, $1 \mathrm{ng} / \mathrm{ml} \mathrm{bFGF}$, and antibiotics, and adipogenic differentiation was performed as described [19]. Treatment with RGZ $(1 \mu \mathrm{M})$ and VCE-003.2 $(1 \mu \mathrm{M})$ in the presence and the absence of T0070907 $(5 \mu \mathrm{M})$ started at the same time as the differentiation process. After a week of differentiation, the mRNA expression for PPAR $\gamma$ isoform 2 (PPAR $\gamma 2$ ), lipoprotein-lipase (LPL), CCAAT/enhancer-binding protein$\alpha$ (CEBPA), adiponectin (ADIPOQ), and fatty acid-binding protein 4 (FABP4) was analyzed as described [19].

\section{PPAR transcriptional assays}

To analyze PPARY transcriptional activity, HEK-293T cells were cultured in 24-well plates and transiently 
co-transfected with the expression vector GAL4-PPAR $\gamma$ and the luciferase reporter vectors GAL4-luc (firefly luciferase) and pRL-CMV (renilla luciferase) using Roti@Fect (Carl Roth, Karlsruhe, Germany). After stimulation, the luciferase activities were quantified using DualLuciferase Assay (Promega, Madison, WI, USA).

\section{Immunoblotting}

Whole cell extracts were obtained by lysing the cells in $\mathrm{NP}-40$ buffer $(50 \mathrm{mM}$ Tris- $\mathrm{HCl} \mathrm{pH} 7.5,150 \mathrm{mM} \mathrm{NaCl}$, $10 \%$ glycerol, and 1\% NP-40) supplemented with protease and phosphatase inhibitors. Lysate concentrations were determined by the Bradford assay (Bio-Rad Laboratories, Hercules, CA, USA). Proteins (30 $\mu \mathrm{g} / \mathrm{lane})$ were separated by SDS-PAGE, transferred onto PVDF membranes, and blocked with PBS-T (PBS + 0.1\% Tween-20) containing 5\% non-fat dry milk for $30 \mathrm{~min}$ at room temperature. Incubation with anti-PPARy (ref. C26H12, Cell Signaling Technology, Beverly, MA, USA) and anti- $\alpha$-actin (ref. AC-74, Sigma-Aldrich, Madrid, Spain) was performed overnight at $4{ }^{\circ} \mathrm{C}$, and washed membranes were incubated with appropriate secondary antibodies coupled to horseradish peroxidase that were detected by an enhanced chemiluminescent reagent.

\section{Animals and surgical lesions}

Male C57BL/6 mice were housed in a room with a controlled photoperiod (06:00-18:00 light) and temperature $\left(22 \pm 1{ }^{\circ} \mathrm{C}\right)$. They had free access to standard food and water and were used at adult age (3- to 4-month-old; 25-30 g weight). All experiments were conducted according to European guidelines (directive 2010/63/EU) and approved by the "Comité de Experimentación Animal" of our university (ref. CEA-UCM 56/2012). For in vivo experiments, mice were anesthesized (ketamine $40 \mathrm{mg} / \mathrm{kg}$ + xylazine $4 \mathrm{mg} / \mathrm{kg}$, i.p.) and subjected to unilateral injections of S. Minnesota LPS (Sigma-Aldrich, Madrid, Spain) into two points of the right striatum following the procedure developed by Hunter et al. [24]. We used the following stereotaxic coordinates from bregma: + $1.18 \mathrm{~mm} \mathrm{AP,}-1.5 \mathrm{~mm} \mathrm{ML}$, and $-3.5 \mathrm{~mm}$ $\mathrm{DV}$, as well as $-0.34 \mathrm{~mm} \mathrm{AP,}-2.5 \mathrm{~mm} \mathrm{ML}$, and $3.2 \mathrm{~mm}$ DV (see details in [24]). At each intrastriatal coordinate, $5 \mu \mathrm{g}$ of LPS in a volume of $1 \mu \mathrm{l}$ of saline was injected slowly $(0.5 \mu \mathrm{l} / 30 \mathrm{~s})$ and the needle was left in place for $5 \mathrm{~min}$ before being slowly withdrawn. This avoids generating reflux and a rapid increase in intracranial pressure. Controls were sham-operated and injected with $1 \mu \mathrm{l}$ of saline using the same coordinates. After the application of LPS or saline, mice were also subjected to pharmacological treatments as described in the following section. The lesions were generated using unilateral administration, the advantage of which is that contralateral structures serve as controls for the different analyses.

\section{Pharmacological treatments and sampling}

LPS-lesioned mice were distributed in three groups and administered i.p. with $10 \mathrm{mg} / \mathrm{kg}$ of VCE-003.2, alone or in combination with $5 \mathrm{mg} / \mathrm{kg}$ of the PPAR $\gamma$ antagonist T0070907 (Cayman Chemical, Ann Arbor, Michigan, USA) [25] or vehicle [DMSO (3.3\%) + Tween $20(2 \%)+$ saline (94.7\%)]. The experiment included a fourth group consisting of sham-operated mice also treated with DMSO-Tween 20-saline. The treatment was initiated approximately $16 \mathrm{~h}$ after the LPS lesion and was repeated daily for 21 days. One day after the last injection, mice were killed by rapid and careful decapitation and their brains were rapidly removed and frozen in 2-methylbutane cooled in dry ice and stored at $-80{ }^{\circ} \mathrm{C}$ for subsequent immunohistochemical analysis in the substantia nigra and qPCR analysis in the striatum.

\section{Real-time qRT-PCR analysis}

Brain coronal slices (around $500 \mu \mathrm{m}$ thick) were made at levels containing the striatum, according to Palkovits and Brownstein Atlas [26]. Subsequently, such structure was dissected and used for qRT-PCR analysis. Cell pellets from the in vitro experiments were also used for qRT-PCR analysis. Total RNA was isolated from the different samples using SurePrep RNA/Protein Purification Kit (Fisher Bioreagents, Madrid, Spain). The total amount of RNA extracted was quantitated by spectrometry at $260 \mathrm{~nm}$ and its purity from the ratio between the absorbance values at 260 and $280 \mathrm{~nm}$. After genomic DNA was removed (to eliminate DNA contamination), single-stranded complementary DNA was synthesized from up to $1 \mu \mathrm{g}$ of total RNA using the commercial kits Rneasy Mini Quantitect Reverse Transcription (Qiazen, Hilgen, Germany) and iScript ${ }^{\mathrm{TM}}$ cDNA Synthesis Kit (Bio-Rad, Hercules, CA, USA). The reaction mixture was kept frozen at $-20{ }^{\circ} \mathrm{C}$ until enzymatic amplification. Quantitative RT-PCR assays were performed using TaqMan Gene Expression Assays (Applied Biosystems, Foster City, CA, USA) to quantify mRNA levels for TNF- $\alpha$ (ref. Mm99999068_m1), IL-1 $\beta$ (ref. Mm00 434228_m1), iNOS (ref. Mm01309902_m1), and COX-2 (ref. Mm00478372_m1), using GAPDH expression (ref. Mm99999915_g1) as an endogenous control gene for normalization. The PCR assay was performed using the 7300 Fast Real-Time PCR System (Applied Biosystems, Foster City, CA, USA), and the threshold cycle (Ct) was calculated by the instrument's software (7300 Fast System, Applied Biosystems, Foster City, CA, USA). Expression levels were calculated using the $2^{-\Delta \Delta C t}$ method. 


\section{Immunohistochemical procedures}

Brains were sliced in coronal sections (containing the substantia nigra) in a cryostat ( $30 \mu \mathrm{m}$ thick) and collected on antifreeze solution (glycerol/ethylene glycol/ PBS; 2:3:5) and stored at $-20{ }^{\circ} \mathrm{C}$ until used. Sections were mounted on gelatin-coated slides and, once adhered, washed in $0.1 \mathrm{M}$ potassium PBS (KPBS) at $\mathrm{pH}$ 7.4. Then, endogenous peroxidase was blocked by 30-min incubation at room temperature in a peroxidaseblocking solution (Dako Cytomation, Glostrup, Denmark). After several washes with KPBS, sections were incubated overnight at room temperature with the following primary antibodies: (i) rabbit polyclonal anti-TH (ChemiconMillipore, Temecula, CA, USA) used at 1/400; (ii) rabbit polyclonal anti-Iba-1 antibody (Wako Chemicals, Richmond, VA, USA) used at 1/300; or (iii) monoclonal rat anti-mouse Cd68 antibody (AbD Serotec, Oxford, UK) used at $1 / 200$. Dilutions were carried out in KPBS containing 5\% normal horse serum and $0.1 \%$ Triton X100 (Sigma Chem., Madrid, Spain). After incubation, sections were washed in KPBS, followed by incubation with the corresponding biotinylated secondary antibody (1/400) (Vector Laboratories, Burlingame, CA, USA) for $1 \mathrm{~h}$ at room temperature. Avidin-biotin complex (Vector Laboratories, Burlingame, CA, USA) and 3,3'diaminobenzidine substrate-chromogen system (Dako Cytomation, Glostrup, Denmark) were used to obtain a visible reaction product. Negative control sections were obtained using the same protocol with omission of the primary antibody. A Leica DMRB microscope and a DFC300FX camera (Leica, Wetzlar, Germany) were used for the observation and photography of the slides, respectively. For quantification of the intensity of $\mathrm{TH}$, Iba-1, or CD68 immunostaining either in the substantia nigra (both ipsilateral and contralateral sides), we used the NIH Image Processing and Analysis software (ImageJ; NIH, Bethesda, MD, USA) using 4-5 sections, separated approximately by $200 \mu \mathrm{m}$, and observed with $\times 5-20$ objectives depending on the method and the brain area under quantification. In all sections, the same area of the substantia nigra pars compacta was analyzed. Analyses were always conducted by experimenters who were blinded to all animal characteristics. Data were expressed as percentage of immunostaining intensity in the ipsilateral (lesioned) side over the contralateral (non-lesioned) side.

Immunofluorescence was used for a double-labeling analysis with $\mathrm{TH}$ and $\mathrm{Cd} 68$ in sections containing the substantia nigra pars compacta. After pre-incubation for 20 min with Tris-buffered saline with $1 \%$ Triton X-100 (pH 7.5), sections were sequentially incubated overnight at $4{ }^{\circ} \mathrm{C}$ with a monoclonal rat anti-mouse $\mathrm{Cd} 68$ antibody (AbD Serotec, Oxford, UK) used at $1 / 200$, followed by washing in a Tris-buffered saline and a new incubation (at $37{ }^{\circ} \mathrm{C}$ for $2 \mathrm{~h}$ ) with an anti-rat secondary antibody made in donkey (1/200) conjugated with Alexa 488 (Life Technologies-Thermofisher Scientific, Waltham, MA, USA) rendering green fluorescence. Sections were then washed again and incubated overnight at $4{ }^{\circ} \mathrm{C}$ with a polyclonal rabbit anti-TH (Chemicon-Merck Millipore, Darmstadt, Germany) used at 1/200, again followed by washing in a Tris-buffered saline and a new incubation (at $37{ }^{\circ} \mathrm{C}$ for $2 \mathrm{~h}$ ) with an anti-rabbit secondary antibody made in goat (1/200) conjugated with Alexa 546 (Invitrogen, Carlsbad, CA, USA) rendering red fluorescence. Sections were counter-stained with nuclear stain TOPRO-3-iodide (Molecular Probes, Eugene, OR, USA) to visualize cell nuclei. A SP5 Leica confocal microscope was used for slide observation and photography.

\section{Docking analysis}

Ligand docking was performed using the AutoDock4 [27] and the Vina software [28] with the virtual screening tools PyRx [29] and PyMOL [30]. The receptor model used was the PDB reference (RCSB Protein Data Bank accession code) 2Q59 and 3B0R [20], and 4EMA [31]. The search space for the docking, around the receptor molecule surface, was set according to previous findings about several binding sites for different ligands. Once analysis has been performed, AutoDock Vina provides the estimated binding affinity value, which is the sum of the intermolecular energy, due to the interaction between both molecules, and the torsional freeenergy penalty, due to the conformation adopted by these molecules to properly fit the interaction surface. A negative value indicates that the bond is thermodynamically stable, whereas a positive value means instability. Search space for the docking was set around the binding sites described previously [20].

\section{Data analysis}

Data were subjected to the one-way analysis of variance followed by the Student-Newman-Keuls, Tukey, or the Bonferroni multiple comparison tests.

\section{Results}

Determination of $\mathrm{CB}_{1} / \mathrm{CB}_{2}$ receptor binding for VCE-003.2 VCE-003.2 was synthesized as described in a previous study [19], in which its pharmacodynamic properties, in particular its activity as a PPARY activator, were already investigated using transcriptional assays [19]. VCE-003.2 is a derivative of CBG, a non-psychoactive cannabinoid present in the Cannabis plant that does not exhibit any activity at the $C_{1}$ receptor [32]. We have recently confirmed that $\mathrm{CBG}$ binds the $\mathrm{CB}_{2}$ receptor also with a poor affinity in the micromolar range [17]. Therefore, it was expected that its quinone derivative VCE-003.2 has no affinity at both $\mathrm{CB}_{1}$ and $\mathrm{CB}_{2}$ receptors. To confirm 
that, we conducted radioligand binding assays using membranes purified from cells transfected with human $\mathrm{CB}_{1}$ or $\mathrm{CB}_{2}$ receptors. Our data demonstrated that a high concentration of VCE-003.2 $(40 \mu \mathrm{M})$ displaced radioligand binding to both $\mathrm{CB}_{1}$ and $\mathrm{CB}_{2}$ receptors with a percentage in both cases lower than $50 \%$, then indicating negligible affinity for both receptors with predicted Ki always $>40 \mu \mathrm{M}$ in both cases.

\section{Anti-inflammatory and neuroprotective effects of VCE-003.2 in LPS-lesioned mice}

Given the activity of VCE-003.2 at the PPARY receptors, which is an important factor involved in the control of inflammation, we wanted to evaluate its antiinflammatory/neuroprotective properties in a typically in vivo inflammatory model of PD, LPS-lesioned mice. It is likely that, in the absence of $\mathrm{CB}_{2}$ receptor activity for VCE-003.2, such beneficial effects, if they exist, should be possibly mediated by enhancing PPAR $\gamma$ signaling. First, we analyzed TH immunostaining in the substantia nigra pars compacta and demonstrated a reduction of immunoreactivity in LPS-lesioned mice $(F(3,17)=5.21$, $p<0.05$; see Fig. 1) in concordance with the previous data $[6,7]$, and evident here comparing the lesioned ipsilateral side with the non-lesioned contralateral side (Fig. 1). In addition to these quantitative data, the morphological analysis of the immunostained substantia nigra showed an evident reduction in neuropil (Fig. 1), possibly reflecting neurite losses in nigral neurons. The reduction in immunoreactivity levels and also the deteriorated aspect of neuropil in nigral neurons were reversed by the treatment with VCE-003.2 (Fig. 1). In addition, we also found a lowering effect of VCE-003.2 on the intense microgliosis provoked by LPS and revealed by Iba-1 $(F(3,18)=6.76, p<0.005$; see Fig. 2) and Cd68 $(F(3,19)=5.03, p<0.05$; see Fig. 3$)$ immunostaining in the substantia nigra. Such microgliosis was evident not only by the elevated immunoreactivity but also by the presence of microglial cells (labeled with Iba-1) with ameboid aspect (activated state) compared with the ramified form (quiescent state) currently found in controls (Fig. 2). The treatment with VCE-003.2 changed this activated morphology towards a classic resting aspect (Fig. 2). In addition, using a double immunofluorescence analysis for $\mathrm{TH}$ and $\mathrm{Cd} 68$, we confirmed that this reactive microgliosis was specifically located inside and surrounding the substantia nigra pars compacta and associated with the loss of TH-positive neurons. This analysis is presented as a supplementary figure (see Additional file 1) and demonstrates the proximity of TH and Cd68 labeling, but the expected lack of any overlapping.

We also analyzed by qPCR several proinflammatory markers typical of the activated microglial cells recruited

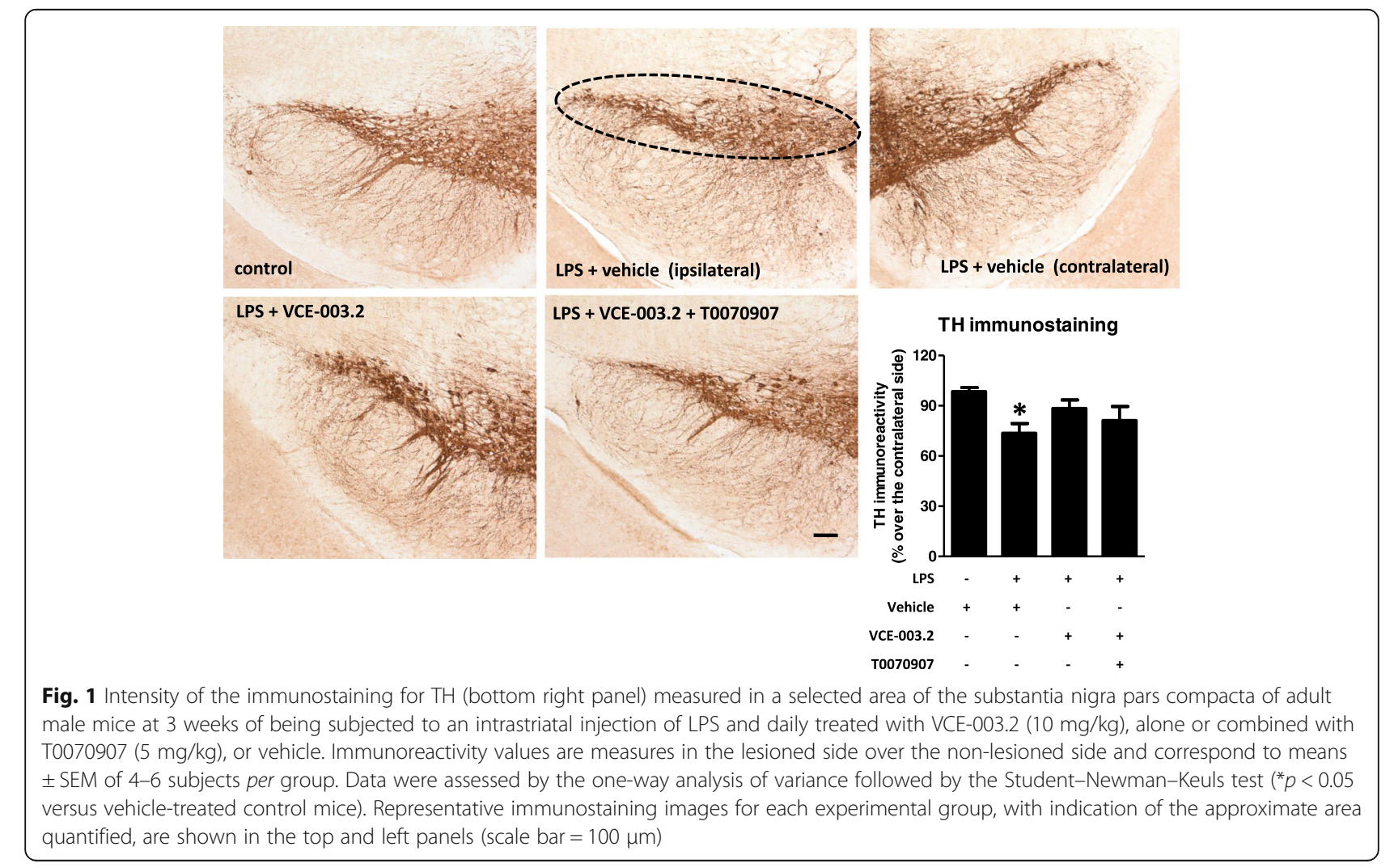




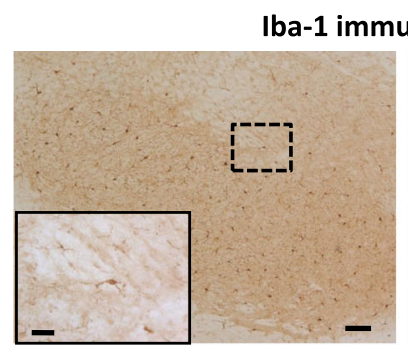

control

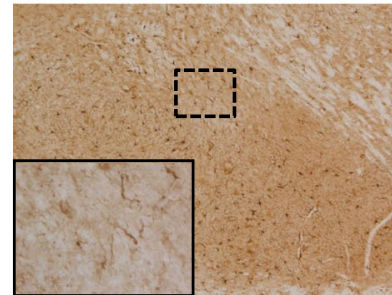

LPS + VCE-003.2

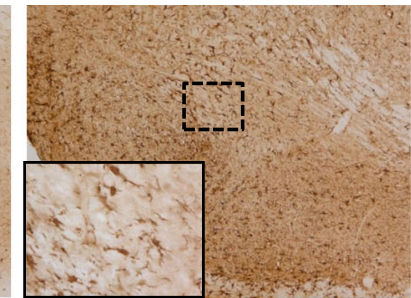

LPS + vehicle (ipsilateral)

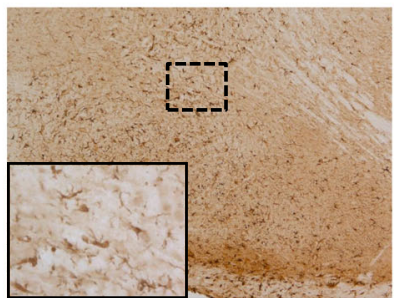

LPS + VCE-003.2 + T0070907

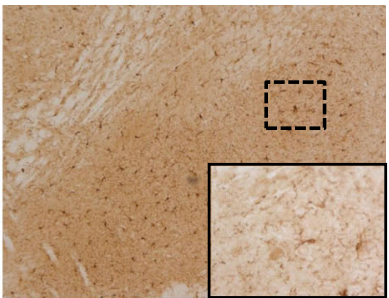

LPS + vehicle (contralateral)

lba-1 immunostaining

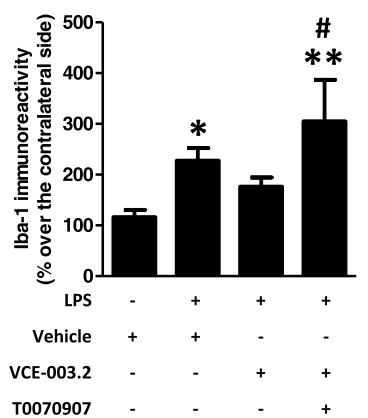

Fig. 2 Intensity of the immunostaining for lba-1 (bottom right panel) measured in a selected area of the substantia nigra pars compacta of adult male mice at 3 weeks of being subjected to an intrastriatal injection of LPS and daily treated with VCE-003.2 (10 mg/kg), alone or combined with T0070907 $(5 \mathrm{mg} / \mathrm{kg})$, or vehicle. Immunoreactivity values are measures in the lesioned side over the non-lesioned side and correspond to means \pm SEM of 4-6 subjects per group. Data were assessed by the one-way analysis of variance followed by the Student-Newman-Keuls test $\left({ }^{*} p<0.05\right.$, ${ }^{* *} p<0.01$ versus vehicle-treated control mice; ${ }^{\#} p<0.05$ versus VCE-003.2-treated LPS-lesioned mice). Representative Iba-1 immunostaining images for each experimental group are shown in the top and left panels (scale bar $=100 \mu \mathrm{m}$ ), including a specific inlet showing the morphological characteristics of Iba-1-labeled cells (scale bar $=25 \mu \mathrm{m}$ )

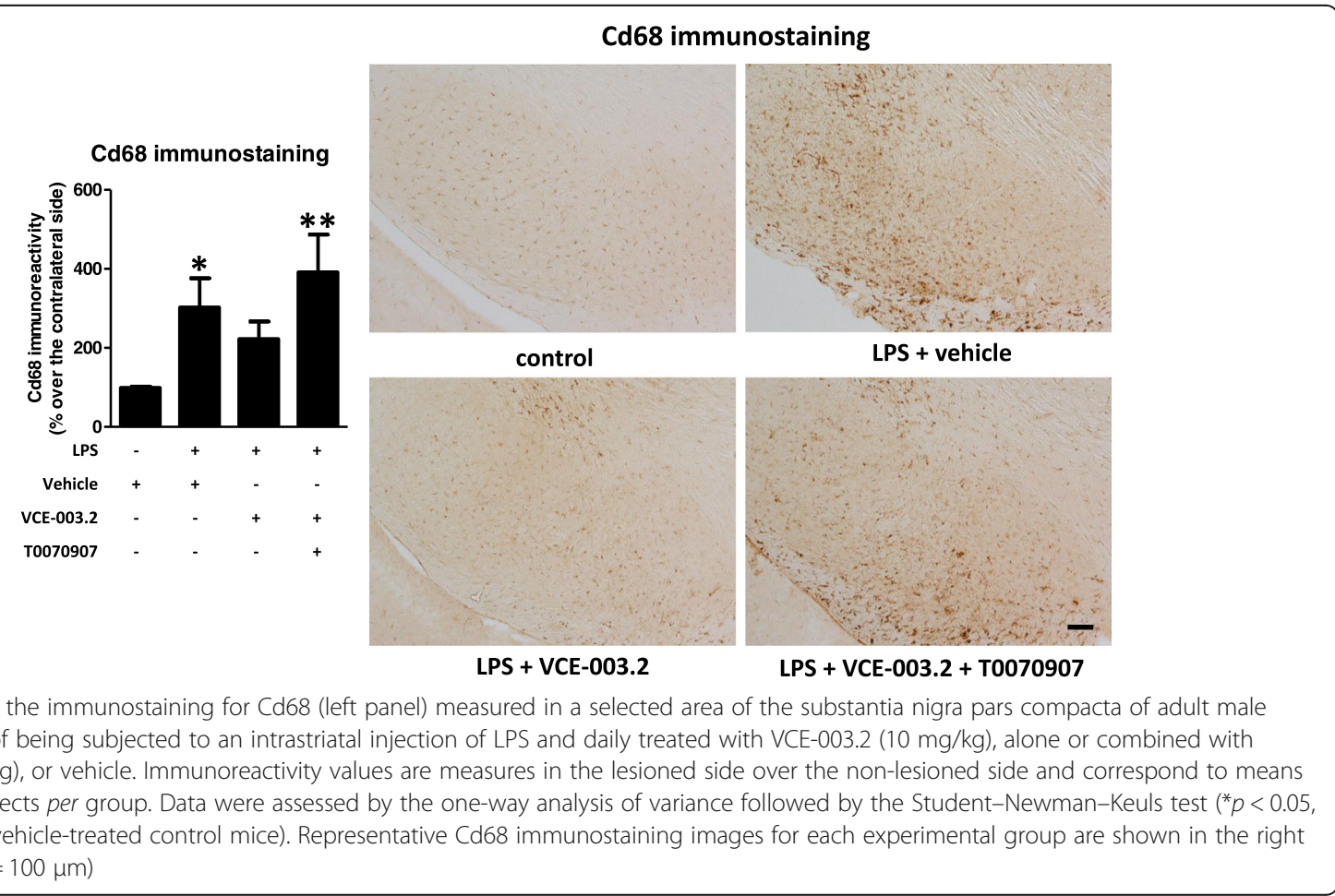


at the lesioned ipsilateral striatum, always compared to the non-lesioned contralateral side. As expected, we detected a strong elevation in the expression of two proinflammatory cytokines TNF- $\alpha(F(3,19)=4.375, p<0.05$; Fig. 4) and IL-1 $\beta(F(3,19)=6.472, p<0.005$; Fig. 4$)$, as well as in the proinflammatory enzyme iNOS $(F(3,19)=$ $6.808, p<0.005$; Fig. 4$)$ in the striatum of LPS-lesioned mice, all of them compatible with the microglial activation found in these mice (Figs. 2 and 3). The elevation in iNOS was attenuated by the treatment with VCE-003.2, with differences between vehicle- and VCE-003.2-treated LPS-lesioned mice being statistically significant (Fig. 4). Moreover, the treatment of LPS-lesioned mice with VCE003.2, although did not reach a statistically significant difference compared to vehicle-treated LPS-lesioned animals in TNF- $\alpha$ and IL-1 $\beta$, provoked that the values for both cytokines are no longer statistically different compared to control mice, thus supporting a modest but evident effect (Fig. 4).

The most interesting was that these effects and also those observed with VCE-003.2 on the microglial activation (Iba-1 and Cd68 immunostaining) disappeared when the CBG derivative was co-administered with the PPAR $\gamma$ antagonist T0070907 (Figs. 2, 3, and 4), then supporting the involvement of this nuclear receptor in VCE-003.2 effects. The only effect of VCE-003.2 that was not reversed by T0070907 in a statistically significant manner was the recovery in $\mathrm{TH}$ immunostaining, although the pattern of changes showed the expected tendency (Fig. 1). It is also important to remark that, in some cases, e.g., Iba- 1 and Cd68 immunostaining and IL-1 $\beta$ and iNOS gene expression, the values reached after the blockade of PPAR $\gamma$ receptors in VCE-003.2treated LPS-lesioned mice were even elevated when compared to the vehicle-treated LPS-lesioned mice (Figs. 2, 3, and 4). This may suggest the existence of an endogenous basal tone activating PPAR $\gamma$, whose apparent beneficial effects would be eliminated only when these receptors are blocked. Such idea would be concordant with previous data showing that GW9662, another irreversible PPAR $\gamma$ inhibitor, was toxic for dopaminergic neurons in MPTP-treated mice [33].

This evaluation of the neuroprotective effects of VCE003.2 in in vivo models of PD also included experiments in an additional model of parkinsonism, mice lesioned with 6-hydroxydopamine, which, contrarily to LPSlesioned mice, is a model with poor inflammation and glial reactivity and mainly based on oxidative stress derived from mitochondrial dysfunction. These data are presented as a supplementary material (see Additional file 3).

\section{Anti-inflammatory effects of VCE-003.2 against a LPS insult in cultured BV2 cells}

Next, we used some in vitro approaches to further investigate the benefits found with VCE-003.2 in the inflammatory in vivo model of PD. We investigated first the anti-inflammatory profile of VCE-003.2 in cultured BV2 cells exposed to LPS. On the one hand, VCE-003.2 was able to attenuate the LPS-induced release of TNF- $\alpha$ $(F(2,43)=104.4, p<0.0001$; Fig. 5) and reduced the $p$ values compared to controls in the case of IL-1 $\beta(F(2,44)$ $=18.72, p<0.0001$; Fig. 5), with both cytokines being measured in culture media using ELISA kits. On the other hand, this was associated with similar changes measured by qPCR in cell pellets, with elevations after LPS which were attenuated after the treatment with VCE-003.2 for TNF- $\alpha(F(3,27)=8.327, p<0.001$; Fig. 6$)$ and for two proinflammatory enzymes like COX-2 $(F(3,27)=16.10, p$ $<0.0001$; Fig. 6) and $\operatorname{iNOS}(F(3,27)=35.95, p<0.0001$; Fig. 6). Again, in the case of IL- $1 \beta(F(3,27)=5.05, p<0.01$; Fig. 6), the effect of VCE-003.2 consisted in a reduction in $p$ values compared to controls (Fig. 6). However, these effects of VCE-003.2 effects were not inhibited by the PPARY antagonist GW9662; in fact, they were apparently

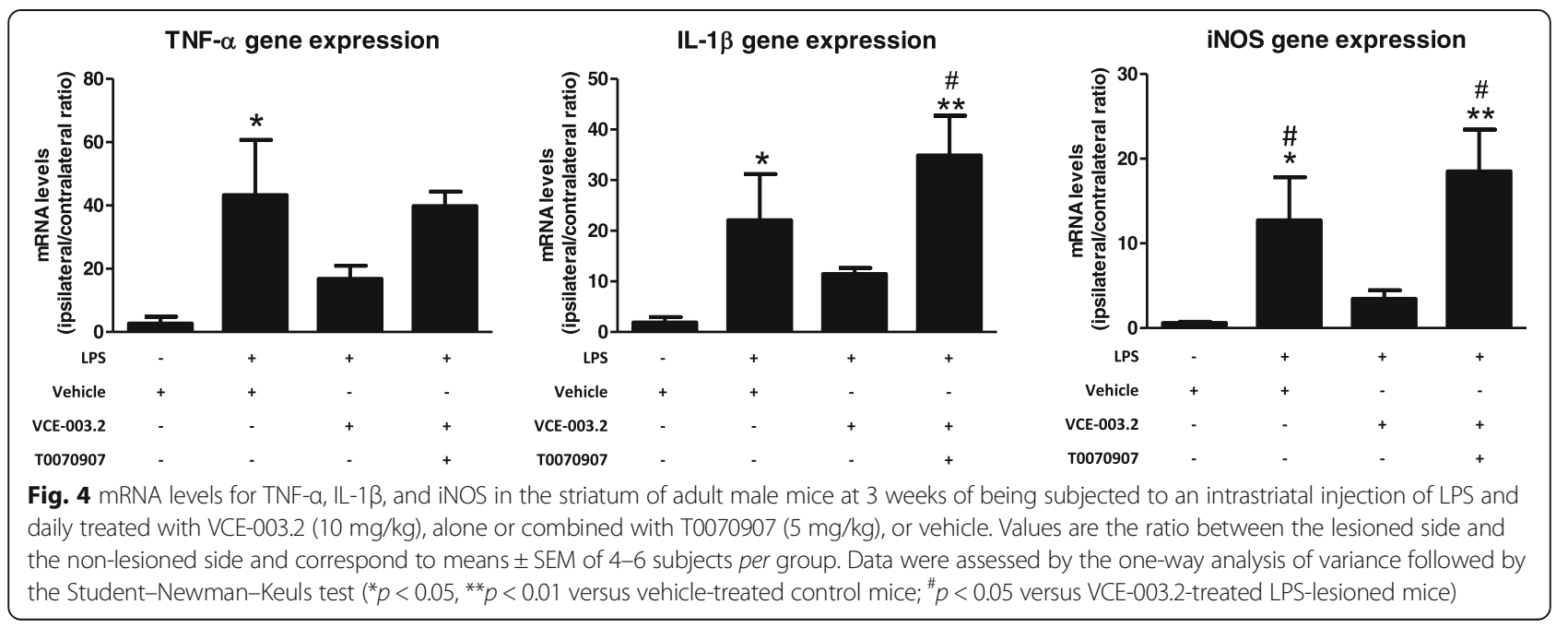




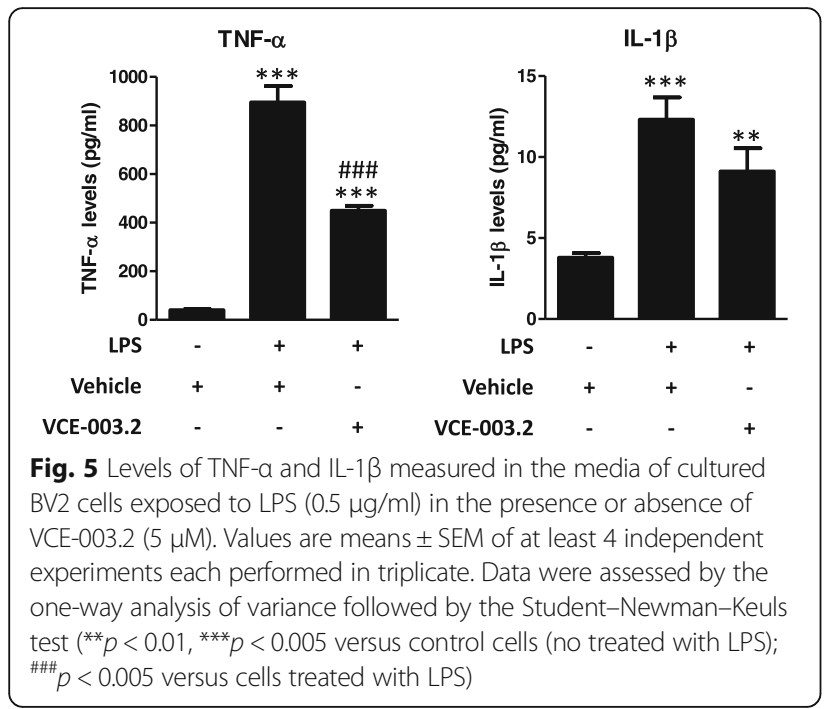

enhanced in the presence of this antagonist (Fig. 6). We do not believe that this result may be due to the change in the PPAR $\gamma$ antagonist because, as mentioned above, GW9662 is other synthetic irreversible PPARy antagonist, which, as T0070907, covalently binds to Cys285 into the PPAR $\gamma$ ligand-binding pocket (LBP). The only difference between both antagonists is a single nitrogen substitution, so that both compounds can be indistinctly used as a tool to investigate PPAR $\gamma$ activation by different ligand activators. Hence, the fact that the effects of VCE-003.2 were not reversed by GW9662, which would presumably occur with T0070907 too, might indicate that, in LPS-treated BV2 cells, VCE-003.2 might act also through PPAR $\gamma$ independent mechanisms, and this may be the consequence of the well-known LPS-induced downregulation of these receptors found in BV2 cells [34] and also in macrophages [35]. However, we do not believe that this may happen in our study, as we have evidence that both RGZ and VCE-003.2 increase the expression of PPAR $\gamma$, which, in general, is known to be upregulated by PPARy ligand agonists, counteracting the repressive effect of LPS on the expression of this nuclear receptor (see Additional file 2). As regards the enhancing action of GW9662 on VCE003.2 effects in LPS-treated BV2 cells, we believe that they may be related to an additive interaction of both at the PPARY LBP derived from a potential activity of GW9662 as partial agonist too. This has been previously described for different biological activities of this class of antagonists [36, 37], whereas, in our hands, both GW9662 and T0070907 exert PPAR $\gamma$ transcriptional activity in a Gal4Luc system, although to a much lesser extent than RGZ and VCE-003.2 (data not shown).

\section{Neuroprotective effects of VCE-003.2 in M-213 neuronal cells exposed to conditioned media generated by cultured BV2 cells exposed to LPS}

The second in vitro approach we used to further explore the neuroprotective properties of VCE-003.2 in PD consisted in investigating its capability to protect cultured M-213 neuronal cells against death induced by exposure to conditioned media generated from cultured BV2 cells overexposed to LPS. This is a classic method to investigate neuroprotection against inflammationdriven neurotoxicity [22]. First, we wanted to evaluate different concentrations of VCE-003.2 and what we found was the classic dual effect of cannabinoids, with low concentrations $(0.1-0.5 \mu \mathrm{M})$ preserving M-213 cells against the inflammatory insult, to a similar extent than RGZ used as a positive control for PPARy, whereas higher concentrations, but not particularly high $(1 \mu \mathrm{M})$, resulted toxic $(F(9,38)=24.95, p<0.0001$; Fig. 7$)$. This was mostly similar to the results found with VCE-003.2 in cultured neural progenitor cells, in which toxicity was evident from a concentration of $2 \mu \mathrm{M}$ [19]. The three

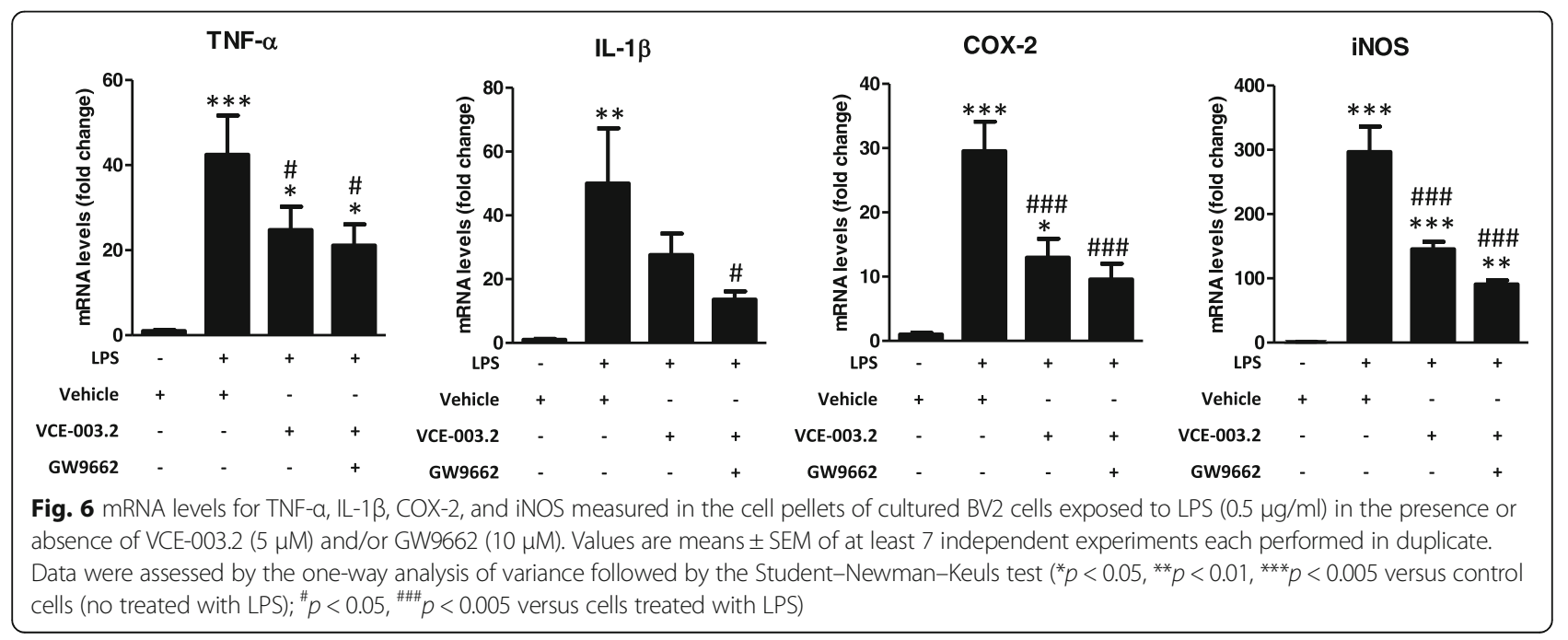




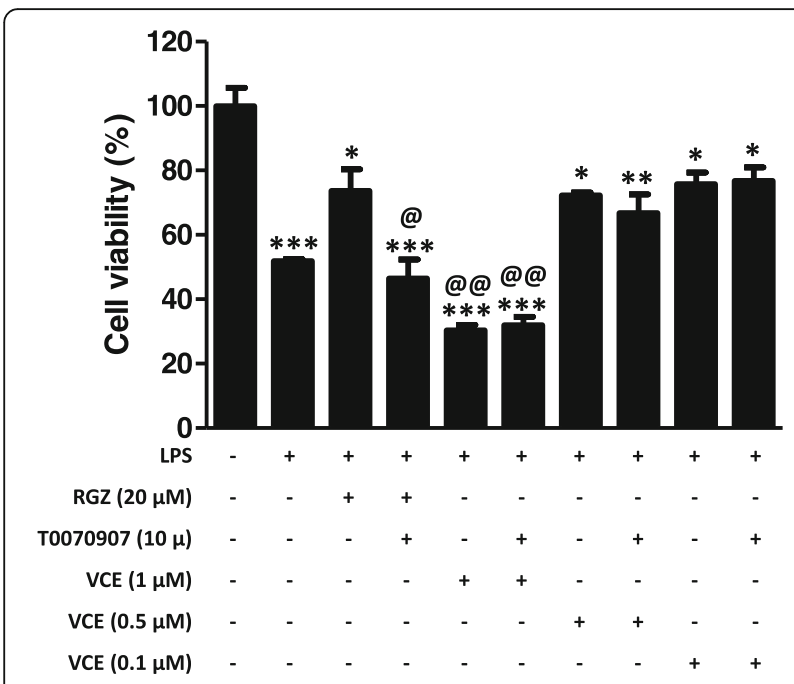

Fig. 7 Cell viability measured in cultured $\mathrm{M}-213$ cells treated with different concentrations of VCE-003.2 (0.1, 0.5, and 1.0 $\mu \mathrm{M})$ or RGZ $(20 \mu \mathrm{M})$ in the presence or the absence of T0070907 $(10 \mu \mathrm{M})$ and exposed to conditioned media generated from LPS-stimulated BV2 cells. The control (100\% of cell viability) consisted in M-213 cells that were exposed to conditioned media in the absence of LPS. Values are means \pm SEM of at least 4 independent experiments each performed in duplicate. Data were assessed by the one-way analysis of variance followed by the Student-Newman-Keuls test $\left({ }^{*} p<0.05\right.$, ${ }^{* *} p<0.01,{ }^{* * *} p<0.005$ compared to the control cells (incubated with conditioned media no generated with LPS); ${ }^{@} p<0.05$, ${ }^{@} p<0.01$ versus cells treated with RGZ, as well as versus cells treated with VCE-003.2 (0.1 and 0.5 MM) combined or not with T0070907 (incubated with conditioned media generated with LPS))

concentrations of VCE-003.2 and RGZ were examined also in the presence of the PPARY receptor inhibitor T0070907 in order to determine whether their effects were mediated by activation of these receptors. However, whereas the effect of RGZ was completely reversed by the PPAR $\gamma$ receptor inhibitor T0070907, this inhibitor was inactive against the effect of VCE-003.2 at the two protective concentrations (Fig. 7), then suggesting the contribution of mechanisms other than the canonic activation of PPARY in these effects. The same happened with the toxic concentration (Fig. 7).

\section{VCE-003.2 binds to the canonical and alternative sites in the PPARy LBP}

We have previously shown that VCE-003.2 is a PPARY partial agonist compared to RGZ [19]. PPAR $\gamma$ receptor ligands can induce a graded response such as full and partial agonism and antagonism that may depend on the mode of interaction and binding to the LBP $[20,38]$. Thus, we were interested to study the potential functionality of the canonical and alternative PPAR $\gamma$ sites involved in the response to VCE-003.2. Luciferase reporter assays were used to measure PPAR $\gamma$-dependent transcription, and RGZ $(F(13,28)=84.77, \quad p<0.0001$; Fig. $8 \mathrm{a})$ and VCE-003.2 $(F(13,35)=15.41, \quad p<0.005$; Fig. 8b) showed increase in PPAR $\gamma$ transactivation. To study the participation of the alternative binding site, the cells were pre-incubated with T0070907 before treating the cells with the agonist ligands. T0070907 did not block the action of VCE-003.2 (Fig. 8b), but it was very effective to block RGZ-induced PPARY transactivation (Fig. 8a) that is consistent with the fact that RGZ activates PPAR $\gamma$ by acting mainly through the canonical binding site [20]. To further analyze the effects of VCE003.2 at this nuclear receptor, we studied the behavior of this compound in the presence of RGZ. To achieve this, GAL4-PPAR $\gamma /$ GAL4-luc co-transfected cells were preincubated with increasing concentrations of VCE-003.2, then treated with $1 \mu \mathrm{M}$ RGZ. VCE-003.2 did not affect RGZ-induced PPAR $\gamma$ transactivation, thus suggesting that VCE-003.2 does not compete with RGZ for the same binding site at the LBP PPAR $\gamma$ (Fig. 8c).

Next, we also studied the action of VCE-003.2 in MSCs, which is a valid cell model to assess endogenous PPARy function related to adipogenic differentiation. MSCs were differentiated to adipocytes in the presence of VCE-003.2 or RGZ with or without T0070907 for 7 days, as reflected the data of mRNA expression for the PPAR $\gamma$-dependent genes PPAR $\gamma 2$, LPL, CEBPA, ADIPOQ, and FABP4 analyzed by RT-PCR. In the absence of an antagonist, both RGZ [PPAR $2: F(3,8)=67.85, p<$ 0.0001; LPL: $F(3,8)=114.4, p<0.0001$; CEBPA: $F(3,8)=$ 27.37, $p=0.0005$; ADIPOQ: $F(3,8)=491.1, p<0.0001$; FABP4: $F(3,8)=50.45, p<0.0001$; Fig. $8 \mathrm{~d}]$ and VCE003.2 [PPAR $\gamma 2: F(3,8)=67.85, p<0.0001$; LPL: $F(3,8)=$ 63.38, $\quad p<0.001 ; \quad$ CEBPA: $\quad F(3,8)=16.29, \quad p<0,005$; ADIPOQ: $F(3,8)=24.67, p=0.0016$; FABP4: $F(3,8)=$ $50.45, p<0.0001$; Fig. 8e] upregulated the expression of these adipogenic-related genes, although to a different extent, thus confirming the differences between a full PPAR $\gamma$ agonist (RGZ) and a PPAR $\gamma$ modulator (VCE003.2) [19]. T0070907 abrogate the effects of both RGZ (Fig. 8d) and VCE-003.2 (Fig. 8e) on the expression of PPAR $\gamma$-dependent genes, indicating that VCE-003.2 is also functional through the canonical LBP.

To confirm the ability of VCE-003.2 to adopt different binding modes, we performed docking simulation studies using crystal structures 3B0R, 4EMA, and 2Q59 deposited in the Protein Data Bank (PDB). Molecular docking demonstrated that VCE-03.2 molecule binds to the hydrophobic core within the 11-helix bundle (canonical site) and also to the side of the $\Omega$ loop $\beta 3-\beta 4$ region in Helix 3 (alternative binding site). Moreover, in the presence of GW9662, VCE-003.2 only binds to the alternative site by interacting with Ser342 in the $\Omega$ loop $\beta 3$ and Gly284 in Helix 3 (Fig. 9). 

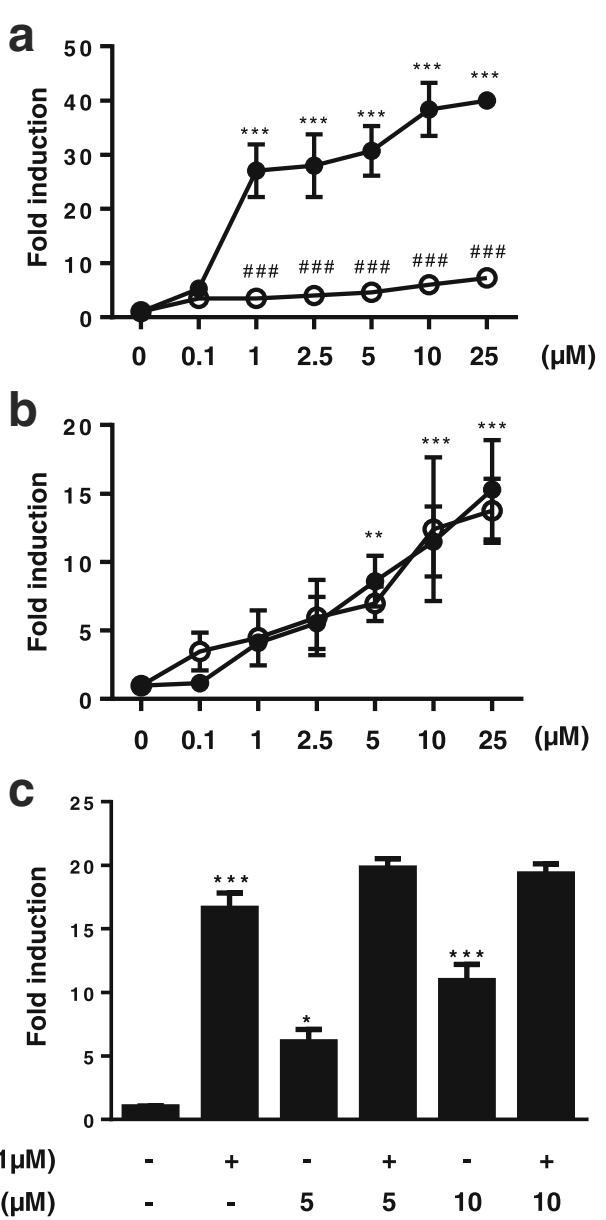

d

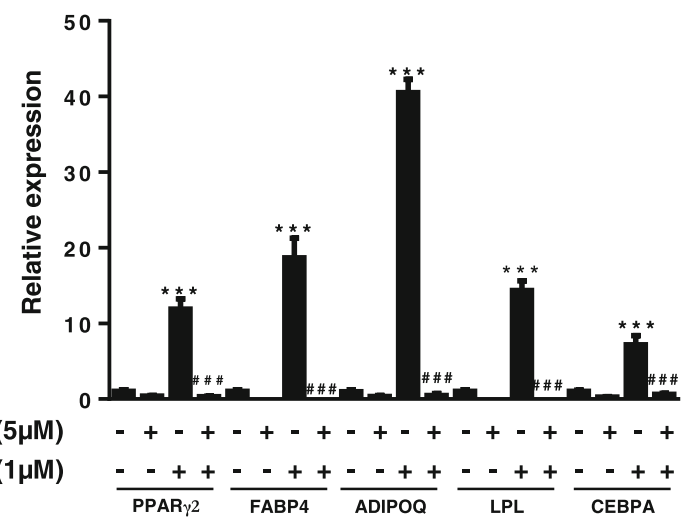

e

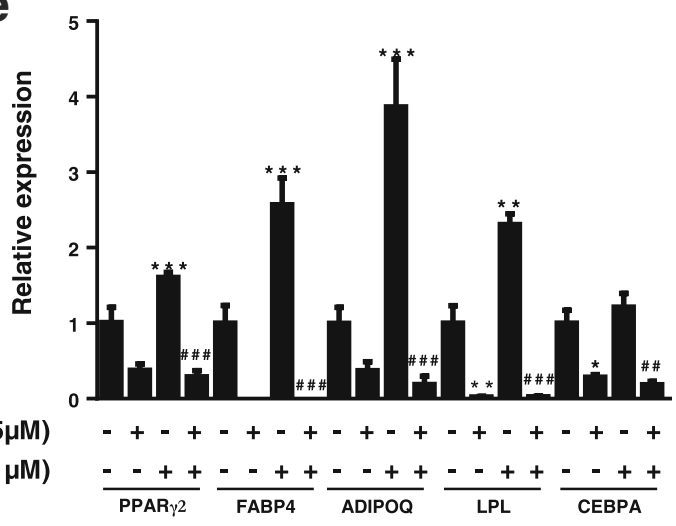
VCE-003.2 $(\mu \mathrm{M})$

Fig. 8 Effects of T0070907 on RGZ- and VCE-003.2-induced PPARY transcriptional activity and MSCs differentiation. HEK-293T cells were transiently transfected with PPARY-GAL4 plus GAL4-luc, pre-incubated with T0070907 (5 $\mu \mathrm{M})$ for $15 \mathrm{~min}$ and then treated with increasing concentrations of either RGZ (a) or VCE-003.2 (b) for $6 \mathrm{~h}$ and luciferase activity measured in the cell lysates (open circles, PPARy ligand; dark circles, PPARy ligand plus T0070907). c Cells were transfected with the same pair of plasmids and treated with RGZ, VCE-003.2, or a combination of both compounds for $6 \mathrm{~h}$ and luciferase activity measured in the cell lysates. T0070907 prevented $\mathbf{d}$ RGZ- and e VCE-003.2-induced adipogenic differentiation in MSCs. The cells were differentiated in AM in the presence of RGZ and VCE-003.2 in the absence and the presence of T0070907, and adipogenic markers were characterized. Gene expression of adipogenic markers such as PPARY2, LPL, FABP4, CEBPA, and ADIPOQ were measured after 7 days of differentiation. Data were assessed by the one-way analysis of variance followed by the Tukey test $\left({ }^{*} p<0.05,{ }^{* *} p<0.01,{ }^{* * *} p<0.001\right.$ RGZ or VCE-003.2 compared to the control cells; ${ }^{\# \#} p<0.01,{ }^{\# \# \#} p<0.001$ RGZ or VCE-003.2 + T0070907 compared to RGZ- or VCE-003.2-treated cells)

\section{Discussion}

Whether neuroinflammation and microglia activation is a consequence or a cause of nigral cell deterioration and death in PD has been a controversial issue for years. However, it appears that presently, there is a general consensus about the important pathogenic role played by glial activation in this disease [39], with increasing evidence supporting that glia-driven inflammation contributes to the progressive degeneration of nigral dopaminergic neurons even in early phases of PD in patients [40]. Such situation may be experimentally reproduced using LPS insults into the nigrostriatal area [24], but it can be also found in other experimental models of PD [41] and identified in postmortem PD brains at autopsy [42]. In addition, epidemiological data support that the regular use of non-steroidal antiinflammatory drugs (e.g., ibuprofen) reduces the risk of developing PD [43], a fact that gives an instrumental value to the control of inflammation in PD. Based on this idea, different anti-inflammatory agents have been investigated, at preclinical and even clinical levels, with variable success in $\mathrm{PD}$. This includes inhibitors of iNOS or COX-2, non-steroidal anti-inflammatory drugs, the antibiotic minocycline, piaglitazone and other PPAR activators, purinergic P2X receptor antagonists, and immunosuppressants $[39,42]$.

Cannabinoids have been also investigated for the reduction of inflammatory events in PD using mainly selective $\mathrm{CB}_{2}$ receptor agonists $[2,44]$. The rationale to do that is based on the frequent upregulatory responses 


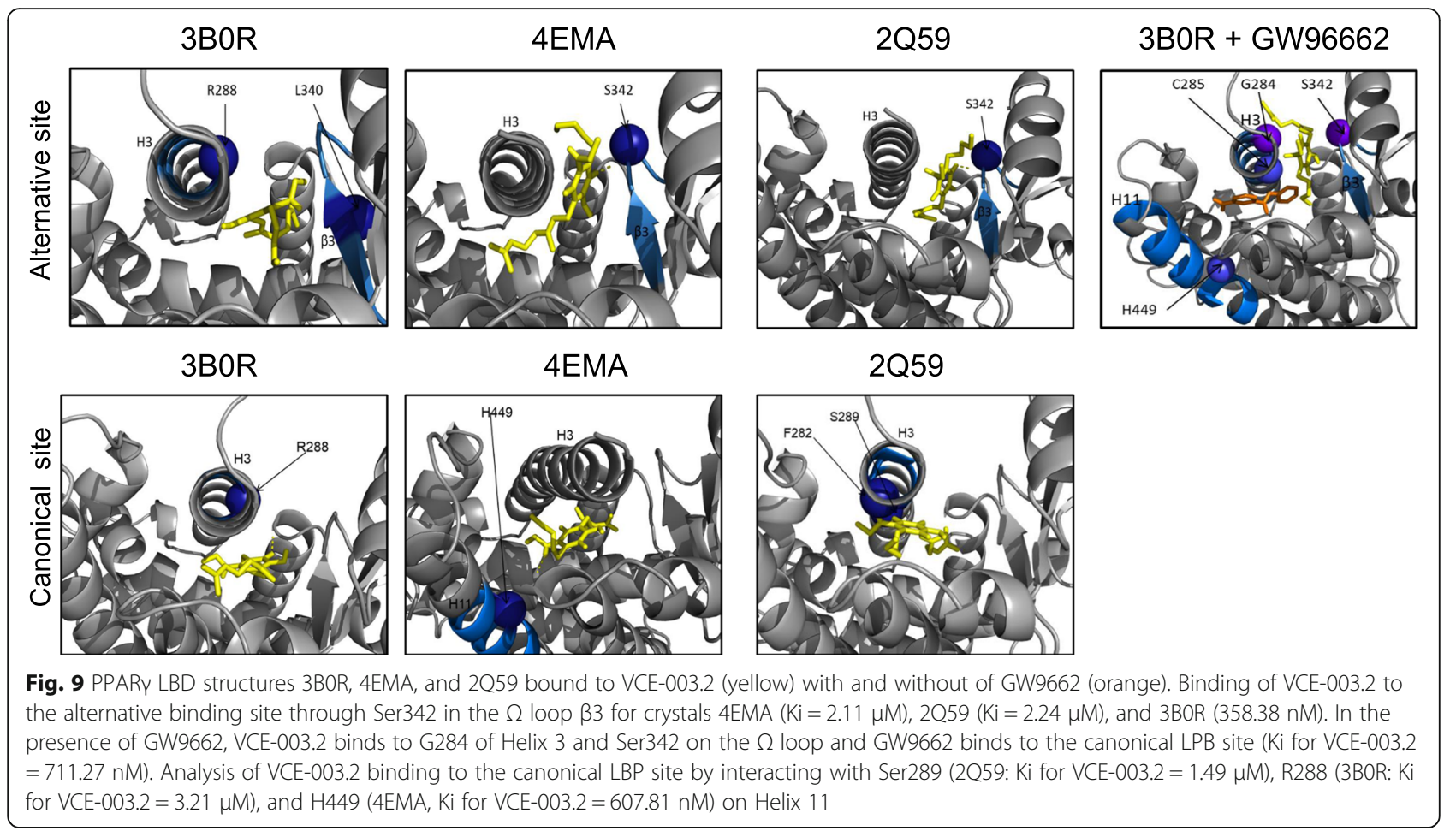

elicited by these receptors, predominantly in microglial cells and infiltrated macrophages recruited at the CNS areas lesioned in PD $[4,6]$, as well as on the anti-inflammatory and neuroprotective effects derived from the selective activation of these upregulated receptors $[4,6,7,9]$. However, another line of evidence may derive from the possibility to target PPAR $\gamma$ receptors with certain cannabinoids in PD. Such evidence is based on (i) the relevant role played by these nuclear receptors in the control of inflammation in numerous pathological conditions [45, 46]; (ii) the well-described PPAR $\gamma$-mediated anti-inflammatory activity of certain cannabinoids in different models of central and peripheral inflammation [11]; and (iii) the effects of noncannabinoid PPAR $\gamma$ activators (e.g., thiazolidinediones [14]) in PD. PPAR receptors function as lipid sensors forming heterodimers with the retinoic acid $\mathrm{X}$ receptor and binding to regulatory DNA elements so-called peroxisome proliferator response elements (PPREs), then regulating transcription of a wide range of genes [47]. The three different PPAR isotypes $(-\alpha,-\beta / \delta$, and $-\gamma)$ are expressed in all cell types in the brain $[48,49]$, and all of them, by functioning in an integrated manner as a complex system, so-called the PPAR triad, have been reported to have neuroprotective properties (reviewed recently in [47]).

In the present study, we attempted to activate PPAR $\gamma$ receptors using a CBG derivative, VCE-003.2, which has been previously found to be partial agonist at these receptors, and to investigate its potential in experimental models of PD. Thus, VCE-003.2 was investigated in a classic inflammatory rodent model of PD generated by intrastriatal application of LPS. This insult enhances reactive microgliosis, reflected by elevated Iba- 1 and Cd68 immunostaining in the substantia nigra, in parallel to an elevation in the expression of proinflammatory markers in the striatum, including the cytokines TNF- $\alpha$ and IL$1 \beta$, and, in particular, iNOS. This is a pro-inflammatory enzyme which has been found to strongly contribute to deteriorate neuronal homeostasis in PD in conditions of reactive gliosis [50-52], a fact reflected in the loss of $\mathrm{TH}$-positive neurons found here. We previously reported that the same proinflammatory markers were strongly elevated by the LPS insult and such elevations were partially reversed by the selective activation of $\mathrm{CB}_{2}$ receptors [6]. Using VCE-003.2, which does not activate $\mathrm{CB}_{2}$ receptors, we found the same response, reduction in the microglial reactivity in the substantia nigra and a marked reduction in the toxicity generated by these activated glial cells, which is reflected in the low levels of proinflammatory markers measured in the striatum of those LPS-lesioned animals treated with VCE-003.2. Such beneficial effects influenced the loss of TH-positive neurons in the substantia nigra, which was partially reduced. Our study also confirmed the involvement of an activation of PPAR $\gamma$ signaling in VCE-003.2 effects in LPS-lesioned mice, so in conditions of elevated glial reactivity and local inflammatory events. Such conclusion derives from the observation that the improvements reached with this CBG derivative in reactive microgliosis 
and the expression of proinflammatory markers disappeared when PPARY receptors were blocked with a selective inhibitor that interacts with the canonical PPAR $\gamma$ LBP. Even, in some cases, the levels of reactive microgliosis and proinflammatory events appeared to be much higher after the blockade of PPAR $\gamma$ receptors, thus indicating the possible existence of an intrinsic endogenous activity of these nuclear receptors limiting inflammatory events that would disappear after the blockade with T0070907. A similar response was found in the study with VCE-003.2 conducted in experimental models of Huntington's disease [19]. In this sense, it has been shown that endogenous fatty acid ligands such as $15 \mathrm{~d}-\mathrm{PGJ}_{2}$ and 5-oxo-ETE covalently bind to Cys285 in the PPARy LBP and its transcriptional activities can be inhibited by T0070907 [53]. Thus, it is conceivable that in brain inflammatory conditions, some eicosanoids are produced to limit neuronal damage, and therefore, blocking this protective response would result in a more exacerbated damage.

Our in vivo study in LPS-lesioned mice was followed by investigation of the anti-inflammatory and neuroprotective properties of VCE-003.2 in a couple of in vitro experimental approaches using cultured LPS-exposed BV2 cells, alone or in combination with M-213 neuronal cells. Our objective was to confirm and, eventually, further explore in vitro the VCE-003.2-induced reduction in the LPS-induced generation of proinflammatory mediators, an objective that was completely attained with the first of the two in vitro approaches. Using only these microglia-related cells, we observed the expected increase in TNF- $\alpha, \mathrm{IL}-1 \beta, \mathrm{COX}-2$, and iNOS elicited by persistent exposure to LPS, which has been previously reported in other studies [54] and how VCE-003.2 was able, in general, to attenuate these responses. The second in vitro approach used in this study was aimed at confirming the capability of VCE-003.2 to protect neurons against glia-driven inflammatory insults. We generated conditioned media from cultured BV2 cells overexposed to LPS and added these media to cultured M-213 neuronal cells in combination with VCE-003.2 to determine its effects on cell viability. Again, VCE-003.2, used at low concentrations, was able to provide neuroprotection. We found that the in vitro antiinflammatory, neuroprotective, and transcriptional (see below) activities of VCE-003.2 were not inhibited by either GW9662 or T0070907, which are PPARy antagonists commonly used to discriminate between PPAR $\gamma$ dependent and PPAR $\gamma$-independent activities. However, this assumption is no longer valid, as there is evidence of alternative binding sites in the PPAR $\gamma$ LBP that are functional and not affected by this class of PPARy antagonists. Indeed, our docking and functional assays strongly suggest that VCE-003.2 is a PPAR $\gamma$ partial agonist that mediates biological functions but acting through canonical and alternative PPAR $\gamma$ pathways. Thus, it is not surprising to find that the blockade of PPAR $\gamma$ with either GW9662 or T0070907 did not prevent some of the effects of VCE-003.2, even they were potentiated in some cases. Accordingly, it has been shown that T0070907 enhances the ability of some partial PPAR $\gamma$ agonists such as BVT.13 and nTZDpa to bind the PPARY coactivator TRAP220 [20]. Equivalent data have been found for other biological activities $[36,37]$, as has been indicated in the "Results" section.

There is experimental evidence in the literature indicating that persistent LPS exposure in BV2 cells causes a downregulation in the expression of PPAR $\gamma$ receptors, which has been proposed to be elicited by elevated TNF- $\alpha$ synthesis $[34,35]$, as well as by an expected upregulation of $\mathrm{NF \kappa B}$ signaling [55]. We found that VCE-003.2, as well as RGZ, induces the expression of PPAR $\gamma$ at the protein level and prevented LPS-induced downregulation of this protein. Since PPAR $\gamma$ gene expression is also upregulated by PPAR $\gamma$ ligands, our results further support a role for PPAR $\gamma$ as a major pathway activated by VCE-003.2. Nevertheless, we cannot exclude that VCE-003.2 induces PPAR $\gamma$-independent effects and preliminary results indicates that this CBG derivative is also a dual inhibitor of the FAAH and MAGL activity (unpublished data) and is also an antioxidant (see Additional file 3). Thus, further research is warranted to investigate the mechanism of action of VCE-003.2 in neuroinflammatory conditions and to fully understand the differences between the in vivo (LPS-lesioned mice) and in vitro results regarding blockade by classic PPARy antagonists. A possible explanation may be based on the differences between in vivo (complete cytoarchitecture) and in vitro (isolated cell populations) models. In this sense, it has been shown that serotonin metabolites, an important neurotransmitter with a potential relevant role in PD, binds and activates PPAR [56], and it will be of interest to analyze the potential synergistic or additive activity of serotonin and VCE003.2 on the PPARY pathway. If the serotonin tone is lowered in PD patients, it will be possible to increase this tone in the presence of VCE-003.2, at least acting on PPARy signaling.

Lastly, our study also addressed an additional objective as investigating the neuroprotective potential of VCE003.2 dependent on its antioxidant profile in an experimental model of PD having poor microglial reactivity (see Additional file 3). We used 6-hydroxydopaminelesioned mice, in which, as mentioned above, several antioxidant phytocannabinoids, such as cannabidiol, $\Delta^{9}$ tetrahydrocannabinol and $\Delta^{9}$-tetrahydrocannabidivarin, had been able to preserve TH-positive neurons in the substantia nigra through effects dependent on their 
cannabinoid receptor-independent antioxidant properties $[7,8,21]$. Our data indicated that this phytocannabinoid derivative was also beneficial in 6-hydroxydopaminelesioned mice. However, contrarily, to the model of LPS lesions, its effects were more evident at the behavioral level (by improving motor impairment) than at the histopathological level. In fact, we were unable to detect a relevant effect on the preservation of $\mathrm{TH}$-positive neurons and we found the expected lack of glial reactivity (see Additional file 3). We assume that these effects may reflect a certain protective effect based on the antioxidant activity of VCE.003-2, but it is possible that they simply reflect a mere symptom-relieving action not associated with preservation of nigral neurons.

\section{Conclusion}

In summary, we have demonstrated that VCE-003.2 is neuroprotective against inflammation-driven neuronal damage in an in vivo model of PD, acting through the activation of the canonic binding site in PPARy receptors. In vitro cellular models reminiscent of the in vivo PD pathology, however, indicated that the effects of VCE-003.2 to limit inflammation may be also exerted through additional mechanisms, including the possibility that VCE-003.2 targets PPARY by acting through two binding sites at the LBP, one that is sensitive to T0070907 (canonical binding site) and other that is not affected by this PPAR $\gamma$ antagonist (alternative binding site). Collectively, our data support the idea of VCE003.2 as a useful neuroprotective agent in PD based on its multi-target properties.

\section{Additional files}

Additional file 1: Figure S1. Double immunofluorescence analysis of Cd68 (in green) and TH (in red) in the substantia nigra pars compacta of adult male mice at 3 weeks of being subjected to an intrastriatal injection of LPS. Top panels show both immunostainings in the contralateral (lesioned) and ipsilateral (non-lesioned) sides (scale bar $=50 \mu \mathrm{m}$ ), whereas bottom panels show the immunostaining for both markers and the merged image in the contralateral (lesioned) side (scale bar $=50 \mu \mathrm{m}$ ), proving the presence of Cd68 immunostaining associated with $\mathrm{TH}$-positive cells, but a complete lack of overlapping, then demonstrating that they correspond to different cells (TH-positive neurons versus Cd68-positive microglial cells) (PDF $757 \mathrm{~kb}$ )

Additional file 2: Figure S2. BV2 cells were seeded at $1 \times 10^{5}$ in $60-\mathrm{mm}$ dishes and $24 \mathrm{~h}$ later treated with RGZ or VCE-003.2 in the absence or the presence of LPS ( $50 \mathrm{ng} / \mathrm{mL}$ ) for $6 \mathrm{~h}$ and the steady state levels of endogenous PPARY and $\beta$-actin detected by western blot (PDF $105 \mathrm{~kb}$ )

Additional file 3: Supplementary information and Supplementary Figures S3-S5. Effects of VCE-003.2 in 6-hydroxydopamine-lesioned mice (PDF $564 \mathrm{~kb}$ )

\section{Abbreviations}

PPARY: Peroxisome proliferator-activated receptor- $\gamma ;$ PPARY2: PPARY isoform 2; ADIPOQ: Adiponectin; $\mathrm{CB}_{1}$ : Cannabinoid receptor type-1; $\mathrm{CB}_{2}$ : Cannabinoid receptor type-2; CBG: Cannabigerol; CEBPA: CCAAT/enhancer-binding protein-a; COX-2: Cyclooxygenase-2; DMEM: Dulbecco's modified Eagle's medium; FABP4: Fatty acid-binding protein 4; FBS: Fetal bovine serum; IL1B: Interleukin-1 $\beta$; iNOS: Inducible nitric oxide synthase; KPBS: Potassium PBS;
LBP: Ligand-binding pocket; LPL: Lipoprotein lipase; LPS: Lipopolysaccharide; MSCs: Mesenchymal stem cells; PBS: Phosphate-buffered saline;

PD: Parkinson's disease; PPREs: Peroxisome proliferator response elements; RGZ: Rosiglitazone; TH: Tyrosine hydroxylase; TNF-a: Tumor necrosis factor-a

\section{Acknowledgements}

The authors are indebted to Yolanda García-Movellán for the administrative assistance.

\section{Funding}

This work has been supported by grants from CIBERNED (CB06/05/0089), MINECO-Biomedicina (SAF2015-68580-C2-1-R), and MINECO Retos-

Colaboración (RTC-2014-1877-1). These agencies had no further role in the study design; collection, analysis, and interpretation of data; writing of the report; or decision to submit the paper for publication.

Availability of data and materials

All data generated or analyzed during this study are included in this published article (and its supplementary information files).

\section{Authors' contributions}

$J F R$, EM, and CG contributed to the study design, coordination, and supervision. MLB, EM, MGC, MGA, and MRP contributed to the VCE-003.2 synthesis and binding analyses. CG, YGG, SC, and JFH contributed to the studies in LPS-lesioned mice. CG and $\mathrm{CP}$ contributed to the studies in 6-hydroxydopamine-lesioned mice. CG, SB, and MGC contributed to the studies in cultured BV2 and M-213 cells. BP and CN contributed to the studies in cultured MSCs and transcriptional assays. CP and EM contributed to the docking analysis. JFR with $C G, S C, C P, M G C, B P$, and SB contributed to the statistical analysis of the data. JFR contributed to the manuscript writing with the revision and approval of all authors. All authors read and approved the final manuscript.

\section{Ethics approval and consent to participate}

All experiments with laboratory animals were conducted according to the European guidelines (directive 2010/63/EU) and approved by the "Comité de Experimentación Animal" of our university (ref. CEA-UCM 56/2012).

Consent for publication

Not applicable.

Competing interests

The authors declare that they have no competing interests.

\section{Publisher's Note}

Springer Nature remains neutral with regard to jurisdictional claims in published maps and institutional affiliations.

\section{Author details}

${ }^{1}$ Instituto Universitario de Investigación en Neuroquímica, Departamento de Bioquímica y Biología Molecular, Facultad de Medicina, Universidad Complutense, 28040 Madrid, Spain. ${ }^{2}$ Centro de Investigación Biomédica en Red de Enfermedades Neurodegenerativas (CIBERNED), Madrid, Spain. ${ }^{3}$ Instituto Ramón y Cajal de Investigación Sanitaria (IRYCIS), Madrid, Spain. ${ }^{4}$ Instituto Maimónides de Investigación Biomédica de Córdoba (IMIBIC), Córdoba, Spain. ${ }^{5}$ Departamento de Biología Celular, Fisiología e Inmunología, Universidad de Córdoba, Córdoba, Spain. ${ }^{6}$ Hospital Universitario Reina Sofía, Córdoba, Spain. Innohealth Group, Madrid, Spain. ${ }^{8}$ Vivacell Biotechnology España, Córdoba, Spain. ${ }^{9}$ Present address: Institute for Science and

Technology in Medicine, Keele University, Newcastle under Lyme, UK.

${ }^{10}$ Present address: Department of Biochemistry and Molecular Biology, Universidad de Las Palmas de Gran Canaria, Las Palmas, Spain. ${ }^{11}$ Present address: Laboratorio de Apoyo a la Investigación. Hospital Universitario Fundación Alcorcón, Alcorcón, Madrid, Spain.

Received: 7 December 2017 Accepted: 8 January 2018

Published online: 16 January 2018

References

1. Lim S, Chun Y, Lee JS, Lee SJ. Neuroinflammation in synucleinopathies. Brain Pathol. 2016;26:404-9. 
2. Fernández-Ruiz J, Romero J, Ramos JA. Endocannabinoids and neurodegenerative disorders: Parkinson's disease, Huntington's chorea, Alzheimer's disease, and others. Handb Exp Pharmacol. 2015;231:233-59.

3. Chiurchiù V, Leuti $\mathrm{A}$, Maccarrone M. Cannabinoid signaling and neuroinflammatory diseases: a melting pot for the regulation of brain immune responses. J Neurolmmune Pharmacol. 2015;10:268-80.

4. Price DA, Martinez AA, Seillier A, Koek W, Acosta Y, Fernández E, et al. WIN55,212-2, a cannabinoid receptor agonist, protects against nigrostriatal cell loss in the 1-methyl-4-phenyl-1,2,3,6-tetrahydropyridine mouse model of Parkinson's disease. Eur J Neurosci. 2009:29:2177-86.

5. Chung YC, Bok E, Huh SH, Park JY, Yoon SH, Kim SR, et al. Cannabinoid receptor type 1 protects nigrostriatal dopaminergic neurons against MPTP neurotoxicity by inhibiting microglial activation. J Immunol. 2011;187:6508-17.

6. Gómez-Gálvez Y, Palomo-Garo C, Fernández-Ruiz J, García C. Potential of the cannabinoid CB2 receptor as a pharmacological target against inflammation in Parkinson's disease. Prog Neuro-Psychopharmacol Biol Psychiatry. 2016;64:200-8

7. García C, Palomo-Garo C, García-Arencibia M, Ramos J, Pertwee R, Fernández-Ruiz J. Symptom-relieving and neuroprotective effects of the phytocannabinoid $\Delta^{9}$-THCV in animal models of Parkinson's disease. $\mathrm{Br}$ J Pharmacol. 2011;163:1495-506.

8. García-Arencibia M, González S, de Lago E, Ramos JA, Mechoulam R, Fernández-Ruiz J. Evaluation of the neuroprotective effect of cannabinoids in a rat model of Parkinson's disease: importance of antioxidant and cannabinoid receptor-independent properties. Brain Res. 2007;1134:162-70.

9. Concannon RM, Okine BN, Finn DP, Dowd E. Differential upregulation of the cannabinoid $\mathrm{CB}_{2}$ receptor in neurotoxic and inflammation-driven rat models of Parkinson's disease. Exp Neurol. 2015;269:133-41.

10. Ternianov A, Pérez-Ortiz JM, Solesio ME, García-Gutiérrez MS, Ortega-Alvaro $A$, Navarrete $F$, et al. Overexpression of $C_{2}$ cannabinoid receptors results in neuroprotection against behavioral and neurochemical alterations induced by intracaudate administration of 6-hydroxydopamine. Neurobiol Aging. 2012;33:421 e1-e16.

11. O'Sullivan SE, Kendall DA. Cannabinoid activation of peroxisome proliferator-activated receptors: potential for modulation of inflammatory disease. Immunobiology. 2010;215:611-6.

12. Fidaleo M, Fanelli F, Ceru MP, Moreno S. Neuroprotective properties of peroxisome proliferator-activated receptor-a (PPARa) and its lipid ligands. Curr Med Chem. 2014;21:2803-21.

13. Agarwal S, Yadav A, Chaturvedi RK. Peroxisome proliferator-activated receptors (PPARs) as therapeutic target in neurodegenerative disorders. Biochem Biophys Res Commun. 2017;483:1166-77.

14. Carta AR, Simuni T. Thiazolidinediones under preclinical and early clinical development for the treatment of Parkinson's disease. Expert Opin Investig Drugs. 2015;24:219-27.

15. Pistis $M$, Melis M. From surface to nuclear receptors: the endocannabinoid family extends its assets. Curr Med Chem. 2010;17:1450-67.

16. Fernández-Ruiz J, Sagredo O, Pazos MR, García C, Pertwee R, Mechoulam R, et al. Cannabidiol for neurodegenerative disorders: important new clinical applications for this phytocannabinoid? Br J Clin Pharmacol. 2013;75:323-33.

17. Granja AG, Carrillo-Salinas F, Pagani A, Gómez-Cañas M, Negri R, Navarrete $C$, et al. A cannabigerol quinone alleviates neuroinflammation in a chronic model of multiple sclerosis. J Neurolmmune Pharmacol. 2012;7:1002-16.

18. Carrillo-Salinas FJ, Navarrete C, Mecha M, Feliú A, Collado JA, Cantarero I, et al. A cannabigerol derivative suppresses immune responses and protects mice from experimental autoimmune encephalomyelitis. PLoS One. 2014;9:e94733.

19. Díaz-Alonso J, Paraíso-Luna J, Navarrete C, Del Río C, Cantarero I, Palomares $B$, et al. VCE-003.2, a novel cannabigerol derivative, enhances neuronal progenitor cell survival and alleviates symptomatology in murine models of Huntington's disease. Sci Rep. 2016;6:29789.

20. Hughes TS, Giri PK, de Vera IM, Marciano DP, Kuruvilla DS, Shin Y, et al. An alternate binding site for PPARY ligands. Nat Commun. 2014;5:3571.

21. Lastres-Becker I, Molina-Holgado F, Ramos JA, Mechoulam R, Fernández-Ruiz J. Cannabinoids provide neuroprotection against 6-hydroxydopamine toxicity in vivo and in vitro: relevance to Parkinson's disease. Neurobiol Dis. 2005;19:96-107.

22. Gómez-Cañas M, Morales P, García-Toscano L, Navarrete C, Muñoz E, Jagerovic N, et al. Biological characterization of PM226, a chromenoisoxazole, as a selective CB2 receptor agonist with neuroprotective profile. Pharmacol Res. 2016;110:205-15.
23. Chiang MC, Cheng YC, Chen HM, Liang YJ, Yen CH. Rosiglitazone promotes neurite outgrowth and mitochondrial function in N2A cells via PPARgamma pathway. Mitochondrion. 2014;14:7-17.

24. Hunter RL, Cheng B, Choi DY, Liu M, Liu S, Cass WA, et al. Intrastriatal lipopolysaccharide injection induces parkinsonism in C57/B6 mice. J Neurosci Res. 2009:87:1913-21.

25. Burton JD, Goldenberg DM, Blumenthal RD. Potential of peroxisome proliferator-activated receptor gamma antagonist compounds as therapeutic agents for a wide range of cancer types. PPAR Res. 2008; 2008:494161.

26. Palkovits M, Brownstein J. Maps and guide to microdissection of the rat brain. Elsevier, 1988

27. Morris GM, Huey R, Lindstrom W, Sanner MF, Belew RK, Goodsell DS, et al. AutoDock4 and AutoDockTools4: automated docking with selective receptor flexibility. J Comput Chem. 2009:30:2785-91.

28. Trott O, Olson AJ. AutoDock Vina: improving the speed and accuracy of docking with a new scoring function, efficient optimization, and multithreading. J Comput Chem. 2010;31:455-61.

29. Wolf LK. New software and websites for the chemical enterprise. Chem Eng News. 2009;87:31.

30. Baugh EH, Lyskov S, Weitzner BD, Gray JJ. Real-time PyMOL visualization for Rosetta and PyRosetta. PLoS One. 2011;6:e21931.

31. Liberato MV, Nascimento AS, Ayers SD, Lin JZ, Cvoro A, Silveira RL, et al. Medium chain fatty acids are selective peroxisome proliferator activated receptor (PPAR) $\mathrm{Y}$ activators and pan-PPAR partial agonists. PLoS One. 2012;7:e36297.

32. Izzo AA, Borrelli F, Capasso R, Di Marzo V, Mechoulam R. Non-psychotropic plant cannabinoids: new therapeutic opportunities from an ancient herb. Trends Pharmacol Sci. 2009;30:515-27.

33. Martin HL, Mounsey RB, Mustafa S, Sathe K, Teismann P. Pharmacological manipulation of peroxisome proliferator activated receptor $\gamma$ (PPAR $)$ reveals a role for anti-oxidant protection in a model of Parkinson's disease. Exp Neurol. 2012;235:528-38.

34. Zhou M, Wu R, Dong W, Jacob A, Wang P. Endotoxin downregulates peroxisome proliferator-activated receptor- $\gamma$ via the increase in TNF-a release. Am J Phys Regul Integr Comp Phys. 2008;294:R84-92.

35. Corsi L, Dongmo BM, Avallone R. Supplementation of omega 3 fatty acids improves oxidative stress in activated BV2 microglial cell line. Int J Food Sci Nutr. 2015;66:293-9.

36. Zizzo G, Cohen PL. The PPAR- $y$ antagonist GW9662 elicits differentiation of M2c-like cells and upregulation of the MerTK/Gas6 axis: a key role for PPAR$\gamma$ in human macrophage polarization. Inflamm (Lond). 2015;12:36.

37. Seargent JM, Yates EA, Gill JH. GW9662, a potent antagonist of PPARY, inhibits growth of breast tumour cells and promotes the anticancer effects of the PPARy agonist rosiglitazone, independently of PPARy activation. $\mathrm{Br} J$ Pharmacol. 2004;143:933-7.

38. Hughes TS, Chalmers MJ, Novick S, Kuruvilla DS, Chang MR, Kamenecka TM, et al. Ligand and receptor dynamics contribute to the mechanism of graded PPARy agonism. Structure. 2012;20:139-50.

39. Tansey MG, Goldberg MS. Neuroinflammation in Parkinson's disease: its role in neuronal death and implications for therapeutic intervention. Neurobiol Dis. 2010;37:510-8.

40. Ouchi Y, Yoshikawa E, Sekine Y, Futatsubashi M, Kanno T, Ogusu T, et al Microglial activation and dopamine terminal loss in early Parkinson's disease. Ann Neurol. 2005:57:168-75.

41. Gao X, Hu X, Qian L, Yang S, Zhang W, Zhang D, et al. Formyl-methionylleucyl-phenylalanine-induced dopaminergic neurotoxicity via microglial activation: a mediator between peripheral infection and neurodegeneration? Environ Health Perspect. 2008;116:593-8.

42. Hirsch EC, Hunot S. Neuroinflammation in Parkinson's disease: a target for neuroprotection? Lancet Neurol. 2009;8:382-97.

43. Chen H, Jacobs E, Schwarzschild MA, McCullough ML, Calle EE, Thun MJ, et al. Nonsteroidal antiinflammatory drug use and the risk for Parkinson's disease. Ann Neurol. 2005:58:963-7.

44. Fernández-Ruiz J, Moro MA, Martínez-Orgado J. Cannabinoids in neurodegenerative disorders and stroke/brain trauma: from preclinical models to clinical applications. Neurotherapeutics. 2015;12:793-806.

45. Laganà AS, Vitale SG, Nigro A, Sofo V, Salmeri FM, Rossetti P, et al, Pleiotropic actions of peroxisome proliferator-activated receptors (PPARs) in dysregulated metabolic homeostasis, inflammation and cancer: current evidence and future perspectives. Int J Mol Sci. 2016;17:E999. 
46. Croasdell A, Duffney PF, Kim N, Lacy SH, Sime PJ, Phipps RP. PPARy and the innate immune system mediate the resolution of inflammation. PPAR Res. 2015;2015:549691.

47. Aleshin S, Strokin M, Sergeeva M, Reiser G. Peroxisome proliferator-activated receptor (PPAR) $\beta / \delta$, a possible nexus of PPARa- and PPARY-dependent molecular pathways in neurodegenerative diseases: review and novel hypotheses. Neurochem Int. 2013;63:322-30.

48. Hall MG, Quignodon L, Desvergne B. Peroxisome proliferator-activated receptor $\beta / \delta$ in the brain: facts and hypothesis. PPAR Res. 2008;2008:780452

49. Heneka MT, Landreth GE. PPARs in the brain. Biochim Biophys Acta. 2007; 1771:1031-45.

50. Arimoto T, Bing G. Up-regulation of inducible nitric oxide synthase in the substantia nigra by lipopolysaccharide causes microglial activation and neurodegeneration. Neurobiol Dis. 2003;12:35-45.

51. Liberatore GT, Jackson-Lewis V, Vukosavic S, Mandir AS, Vila M, McAuliffe WG, et al. Inducible nitric oxide synthase stimulates dopaminergic neurodegeneration in the MPTP model of Parkinson disease. Nat Med. 1999;5:1403-9.

52. Knott C, Stern G, Wilkin GP. Inflammatory regulators in Parkinson's disease: iNOS, lipocortin-1, and cyclooxygenases-1 and -2. Mol Cel Neurosci. 2000;16:724-39.

53. Itoh T, Fairall L, Amin K, Inaba Y, Szanto A, Balint BL, et al. Structural basis for the activation of PPARy by oxidized fatty acids. Nat Struct Mol Biol. 2008;15:924-31.

54. Oh YT, Lee JY, Lee J, Lee JH, Kim JE, Ha J et al. Oleamide suppresses lipopolysaccharide-induced expression of iNOS and COX-2 through inhibition of NFkB activation in BV2 murine microglial cells. Neurosci Lett 2010; 474: 148-153

55. Necela BM, Su W, Thompson EA. Toll-like receptor 4 mediates cross-talk between peroxisome proliferator-activated receptor gamma and nuclear factor-kB in macrophages. Immunology. 2008;125:344-58.

56. Waku T, Shiraki T, Oyama T, Maebara K, Nakamori R, Morikawa K. The nuclear receptor PPARY individually responds to serotonin- and fatty acidmetabolites. EMBO J. 2010;29:3395-407.

\section{Submit your next manuscript to BioMed Central and we will help you at every step:}

- We accept pre-submission inquiries

- Our selector tool helps you to find the most relevant journal

- We provide round the clock customer support

- Convenient online submission

- Thorough peer review

- Inclusion in PubMed and all major indexing services

- Maximum visibility for your research

Submit your manuscript at www.biomedcentral.com/submit

) Biomed Central 